\title{
Fungal glycans and the innate immune recognition
}

\author{
Eliana Barreto-Bergter ${ }^{1 *}$ and Rodrigo T. Figueiredo ${ }^{2 *}$ \\ ${ }^{1}$ Departamento de Microbiologia Geral, Instituto de Microbiologia, Universidade Federal do Rio de Janeiro, Rio de Janeiro, Brazil \\ 2 Instituto de Ciências Biomédicas/Unidade de Xerém, Universidade Federal do Rio de Janeiro, Rio de Janeiro, Brazil
}

\section{Edited by:}

Thomas A. Ficht, Texas A\&M

University, USA

Reviewed by:

Jordi Torrelles, Ohio State

University, USA

Ramesh Vemulapalli, Purdue

University, USA

\section{*Correspondence:}

Eliana Barreto-Bergter,

Departamento de Microbiologia

Geral, Instituto de Microbiologia,

Universidade Federal do Rio de

Janeiro, Centro de Ciências da

Saúde, 21941-902, Rio de Janeiro,

Brazi

e-mail: eliana.bergter@micro.ufrj.br;

Rodrigo T. Figueiredo, Instituto de

Ciências Biomédicas, Universidade

Federal do Rio de Janeiro, Campus

de Xerém, 21941-902, Rio de

Janeiro, Brazil

e-mail: rotifi@icb.ufrj.br
Polysaccharides such as $\alpha$ - and $\beta$-glucans, chitin, and glycoproteins extensively modified with both $\mathrm{N}$ - and $\mathrm{O}$-linked carbohydrates are the major components of fungal surfaces. The fungal cell wall is an excellent target for the action of antifungal agents, since most of its components are absent from mammalian cells. Recognition of these carbohydrate-containing molecules by the innate immune system triggers inflammatory responses and activation of microbicidal mechanisms by leukocytes. This review will discuss the structure of surface fungal glycoconjugates and polysaccharides and their recognition by innate immune receptors.

Keywords: fungal pathogens, polysaccharides, glycoconjugates, pattern recognition receptors, innate immunity

\section{INTRODUCTION}

The fungal cell wall is basically comprised of chitin and $\beta$ glucans, which form an inner rigid core, but several other structurally complex polysaccharides, glycoproteins, enzymes, and lipids have been identified as cell wall components, frequently loosely anchored in the external layer. The fungal cell wall is a dynamic structure where its polymeric constituents are under continuous chemical modification and refolding during their biosynthesis. The cell wall is an excellent target for the action of antifungal agents and also a target for the innate immune recognition, since most of its components are absent from mammalian cells (Masuoka, 2004; Latgé, 2010).

\section{FUNGAL GLYCOCONJUGATES AND POLYSACCHARIDES MANNANS}

The cells of the majority of yeasts contain mannose-containing polysaccharides that are often covalently attached to protein. These polysaccharides are predominantly $\alpha$-D-manopyranans that display a variety of sequences of linkage types in branched structures. A few of the branched mannans carry some $\beta$-Dmanopyranose residues in the side chains (Gorin et al., 1969). In phosphomannans some sugar residues are attached through phosphorodiester linkages (Masuoka, 2004). The cell surface of Candida species is surrounded by a layer enriched in mannosylated glycoproteins and mannosylated lipids. These cell wall mannoproteins (CWMPs) are non-covalently bound to the cell wall as phosphopeptidomannan (PPM) or covalently attached to $\beta(1 \rightarrow 6)$ glucan through remnant glycosylphosphatidylinositol
(GPI) anchors (GPI-anchored proteins), which is in turn attached to $\beta(1 \rightarrow 3)$ glucan or chitin, that form the inner cell wall layer (Masuoka, 2004). PPM containing $\mathrm{O}$ - and $\mathrm{N}$-linked oligosaccharides, can be obtained by autoclaving yeast cells. O-linked mannose residues associated with serine/threonine consist of short chains of $\alpha-(1 \rightarrow 2)$ or $\alpha-(1 \rightarrow 3)$-linked mannose. $N$-linked mannans consist of an inner core elongated by an $\alpha-(1 \rightarrow 6)$-linear chain with branched side chains of $\alpha-(1 \rightarrow 2)$ or $\alpha-(1 \rightarrow 3)$ mannose (Shibata et al., 2003). This structure is similar to that of Saccharomyces cerevisiae, extensively investigated (Stewart and Ballou, 1968). In addition, a number of yeast mannans contain $\beta$-D-mannopyranosyl units in the side chains. $\beta$ - $(1 \rightarrow 2)$-linked mannose residue is also present in the CWMP of some Candida species. C. albicans serotype A, C. glabratta, C. tropicalis, and C. lusitanea have the antigenic factor 6, which corresponds to the Man $\beta(1 \rightarrow 2)-\operatorname{Man} \alpha(1 \rightarrow 2)$ Man $\alpha 1$ residue (Kobayashi et al., 1992).

A cell wall lipoglycan, phospholipomannan (PLM) is another glycoconjugate of $C$. albicans that presents $\beta$-mannosides. It consists of linear chains of $\beta$-(1 $\rightarrow 2)$-Man $p$ units and inositol covalently linked through a phosphodiester bond to a lipid moiety (Trinel et al., 2002). The degree of polymerization of $\beta$ - $(1 \rightarrow 2)$ mannosides chains is up to 19 in C. albicans serotype A strains and short $\beta$ - $(1 \rightarrow 2)$ mannosides chains with predominance of mannotriose in C. albicans serotype B (Trinel et al., 2005). PLM is able to activate inflammasome pathway through a ROS-independent mechanism and this activity seems to be related with the lipid moiety of the molecule. On the other hand, the induction of 
TNF- $\alpha$ production is dependent on the glycan moiety (Devillers et al., 2013). Long glycan chains in PLM favors the formation of complexes with a glycan-binding protein, galectin-3, secreted by macrophages (Fradin et al., 2000).

The role of mannosylation has been extensively investigated in glycosylation deficient mutants. The $\mathrm{Ca}^{+2} / \mathrm{Mn}^{+2}$ ATPase Pmrlp is required for the transport of $\mathrm{Mn}^{+2}$ the Golgi apparatus, where it is necessary as a cofactor for the activity of mannosyltransferases in S. cerevisiae and C. albicans. The pmr1 deficient C. albicans strain shows a strong reduction of the mannose content in the cell wall which reflects a great reduction in the $\mathrm{N}$ - and $\mathrm{O}$ linked glycosylation and phosphomannan synthesis. The pmr1 deficient $C$. albicans also exhibits an increased susceptibility to cell wall noxious agents, and interestingly this strain shows a constitutive activation of Mkclp, a MAP kinase involved in the activation of signaling pathways required for the maintenance of the cell wall integrity (Bates et al., 2005). The phenotype of the pmrp1 deficient $C$. albicans is similar to that observed in the och1 deficient C. albicans, that lacks the 1,6-mannosyltransferase Och1p and, as a consequence, this strain does not form the $\alpha 1,6$-linked polymannose core, while the $O$-glycosylation remains functional (Bates et al., 2006). The double deficient mnt1/mnt2 C. albicans strain lacks the activity of the $\alpha-1,2$-mannosyltransferases, Mnt1p and Mnt2p, what results in the absence of the Man $2-\mathrm{Man}_{5}$ residues, and therefore in the absence of $O$-linked glycosylation. As observed in the C. albicans mutant strains that lack the $N$ linked glycosylation, the mnt1/mnt 2 deficient strain shows an increased susceptibility to cell wall damaging agents (Munro et al., 2005).

Besides its role in the cell wall architecture, the mannosylation plays an important role in the growth and morphology of C. albicans. Although, mannosylation deficient C. albicans strains have been demonstrated to grow in vitro, they present morphological alterations with a deficient filamentation and formation of aggregates by the yeasts (Bates et al., 2005, 2006; Munro et al., 2005). Thus, an adequate mannosylation plays an important role in the C. albicans cell wall integrity and development of the morphological stages of $C$. albicans. Interestingly, while $N$-glycosylation and $O$-glycosylation are required for the cell wall protection against environmental stress, as well as for the development of C. albicans, the synthesis of phosphomannans is dispensable for these aspects, since the selective phosphomannan deficient strain, $m m n 4$, exhibits a similar growth, morphology, and susceptibility to cell wall toxic agents (Hobson et al., 2004).

Mannosylation plays a critical role in the virulence of C. albicans. $\mathrm{N}$ - and $\mathrm{O}$-linked mannans are required for the virulence of $C$. albicans in model of systemic candidiasis, while the presence of phosphomannans is dispensable (Hobson et al., 2004; Bates et al., 2005, 2006; Munro et al., 2005). Although the $\mathrm{N}$ - and $\mathrm{O}$-glycosylation deficient $\mathrm{C}$. albicans strains present a decreased lethality in experimental models of infection, a deficient $N$-glycosylation does not impact the fungal loads during the infection. In contrast, the $O$-glycosylation deficient $C$. albicans strain presents decreased fungal counts in the experimental infection, suggesting that while $N$ - and $O$-glycosylation are required for the virulence, only $O$-glycosylation is necessary for the colonization of the organs during the systemic infections (Munro et al., 2005; Bates et al., 2006). Interestingly, the O-glycosylation deficient $C$. albicans strain $(m n t 1 \Delta / m n t 2 \Delta)$ shows a deficiency in the adhesion to collagen matrices and epithelial cells, while $N$ glycosylation, but nor $\mathrm{O}$-glycosylation, is required for the phagocytosis, binding and cytokine production by macrophages and dendritic cells, suggesting that $O$-linked mannans are involved in the tissue colonization, while $N$-linked mannans are major determinants of the innate immune recognition (Munro et al., 2005; Bates et al., 2006; Cambi et al., 2008). The impact of the glycosylation pathways involved in the mannosylation of fungal glycoconjugates in the biology and virulence of other pathogenic fungi is largely unknown. However, since the extensive mannosylation of glyconconjugates is a conserved pattern found in fungi, the distinct patterns of glycosylation must be determinants for the fungal pathogenesis. Thus, genetic approaches targeting glycosylation pathways in pathogenic fungi must be useful for the comprehension of the fungal virulence and biology.

\section{HETEROPOLYSACCHARIDES WITH MANNAN MAIN CHAINS}

Peptidorhamnomannans (PRMs) are common cell wall components that are distributed in species of the Scedosporium/Pseudallescheria complex and can be isolated by the methodology routinely used in our laboratory (Lopes et al., 2011). Hot aqueous extraction, followed by treatment with Cetavlon in the presence of sodium borate, provided a precipitate of peptidorhamnomannan (PRM), containing carbohydrate $\mathrm{N}$ and $O$-linked to peptide. Methylation-gas chromatography-mass spectrometry (GC-MS) analysis and ${ }^{1} \mathrm{H}$ - and ${ }^{13} \mathrm{C}$-nuclear magnetic resonance (NMR) spectroscopy of PRM showed to contain $\alpha$-Rhap- $(1 \rightarrow 3)$ - $\alpha$-Rhap-side-chain epitopes linked (1 $\rightarrow 3)$ to a $(1 \rightarrow 6)$-linked $\alpha$-Man $p$ core (Pinto et al., 2001). Non-reducing, $O$-linked oligosaccharides were isolated from the PRMs of P. boydii, S. apiospermum, and S. prolificans mycelium by alkaline $\beta$-elimination under reducing conditions (Pinto et al., 2005; Barreto-Bergter et al., 2008, 2011). Three major oligosaccharides were obtained and their structures elucidated based on a combination of techniques including gas chromatography, Electrospray Ionization Mass Spectrometry (ESI-MS), ${ }^{1} \mathrm{H}$ (obs), ${ }^{13} \mathrm{C}$ Heteronuclear Multiple-Quantum Correlation-NMR (HMQC-NMR) spectroscopy and methylation analysis (Pinto et al., 2005). It is interesting to note that these different carbohydrate epitopes present an conserved $\alpha$-Rhap- $(1 \rightarrow 3)-\alpha$-Man $p-(1$ $\rightarrow$ 2)- $\alpha$-Man $p-(1 \rightarrow$ structural component. PRM O-linked oligosaccharides were also isolated from Sporothrix schenckii (Lopes-Bezerra, 2011). Besides glucuronic acid-containing oligosaccharides, a trisaccharide $\alpha$-Rhap $(1 \rightarrow 3)$-Man $p$ (1 $\rightarrow$ 2)-Man-ol similar to a conserved structural component of the Scedosporium/Pseudallescheria complex was identified (Lopes-Bezerra, 2011). PRMs are antigenic and O-linked glycans may account for a significant part of PRM antigenicity, since de$O$-glycosylation treatment has been demonstrated to decrease its antigenicity by $70-80 \%$ (Pinto et al., 2005). Similar results were obtained with A. fumigatus PGM (Leitao et al., 2003) and PRM from S. schenckii (Lopes-Bezerra, 2011). The immunodominance of the $O$-linked oligosaccharide chains was evaluated by testing their ability to inhibit reactivity between PRM and anti-P. boydii antiserum in an ELISA hapten system (Pinto et al., 2005). Up 
to $75 \%$ inhibition occurred with both penta- and hexasaccharides from $P$. boydii PRM. Similar results were observed using penta- and hexasaccharides from $S$. prolificans (our unpublished results). These oligosaccharide alditols blocked recognition between rabbit sera and intact PRM in a dose-dependent manner. Thus, O-linked oligosaccharide chains, despite being the less abundant carbohydrate components of the $P$. boydii and $S$. prolificans glycocomplexes, may account for a significant part of the antigenicity associated with the rhamnomannan component of $P$. boydii/S. prolificans. Rhamnomannans were also isolated from $P$. boydii using a hot alkaline extraction and their structures determined by one-dimensional (1H and 13C) and two-dimensional Correlation Spectroscopy (COSY), Total Correlation Spectroscopy (TOCSY), and Heteronuclear Single Quantum Correlation (HSQC) experiments. The NMR data of fraction II showed at C-1 signals at $\delta$ 97.9/4.981, 101.0/4.967, $102.2 / 5.228$, and $103.9 / 5.060$, typical of terminal $\alpha$-rhamnose units, $O$-3,6-substituted- $\alpha$-mannopyranose, O-2-substituted- $\alpha$ mannopyranose and $\alpha$-Man $p-3-\mathrm{O}$-substituted units, respectively. The signal at $\delta$ 79.9/4.127 confirms the 3-O-substituted $\alpha$-Man $p$ units (Figueiredo et al., 2010).

PRMs derived from $P$. boydii are also involved in the adhesion and infection of an epithelial cell line by $P$. boydii conidia, since the competition with soluble PRM and anti-PRM antibodies are able to inhibit the entry of conidia. Interestingly the determinants involved in the interactions mediated by PRMs seem to require the presence of terminal rhamnose residues that are eliminated by partial hydrolysis, while $O$-glycosylation, the protein portion or mannosyl residues are not necessary (Pinto et al., 2004). P. boydii derived rhamnomannans induce cytokine release by macrophages in a mechanism dependent on TLR4 signaling, as well as degradation of $\mathrm{IkB} \alpha$ and phosphorylation of MAPKs. The induction of cytokine production by these molecules requires the presence of terminal non-reducing residues of rhamnose, since their removal by partial acid hydrolysis abolishes the ability of rhamnomannan to induce cytokine production by macrophages. Thus, structures with terminal rhamnose and mannose residues present in P. boydii rhamnomannans are likely structural motifs involved in TLR recognition (Figueiredo et al., 2010). Thus, rhamnomannans represent a characteristic pattern of glycosylation found on the surface of fungi of the complex Scedosporium/Pseudallescheria, mediating cell infection and the innate immune recognition.

Galactomannans are important structural components of the Aspergillus cell-wall, being widely distributed among most Aspergillus species. Galactomannans are mannose-containing polysaccharides containing terminal D-galactose residues in both furanose and pyranose ring forms, and for the latter both $\alpha$-D and $\beta$-D configurations have been encountered (Latgé et al., 1994). A galactomannan was isolated either from a culture filtrate (Latgé et al., 1994) or from the fungal cell wall of A. fumigatus (Leitao et al., 2003). Its structure was elucidated by acid and enzymatic hydrolysis, partial acetolysis, methylation analysis, and ${ }^{13} \mathrm{C} \mathrm{NMR}$ spectroscopy (Leitao et al., 2003). It consists of a main chain of $(1 \rightarrow 6)$-linked $\alpha$-D-mannopyranosyl residues substituted at $O-2$ by $1-3$ consecutive $\alpha$-D-mannopyranosyl units that were $(1 \rightarrow 2)$-linked. $\beta$-D-Galactofuranosyl-containing side-chains, with $(1 \rightarrow 5)$-links and an average length of approximately
6 units, were attached to O-6 of the mannan core, $\beta-\mathrm{D}$ Gal $f-(1 \rightarrow 5)-[\beta-D-G a l f-(1 \rightarrow 5)]_{0-5}-(1 \rightarrow 6)-\alpha-M a n p-$. Galactomannans have also been shown to exist in a glycosylinositol membrane-bound form. Chemical and enzymatic degradation and mass spectrometry analysis showed that the lipid anchor was a glycosylphosphatidylinositol (GPI), containing a C18-phytosphingosine and a monohydroxylated lignoceric acid, in the lipid portion (Costachel et al., 2005). Summarizing, galactomannans from A. fumigatus are found in three different forms, namely: (1) as a free polysaccharide found in the culture medium, (2) covalently linked to the $\beta(1 \rightarrow 3)$ glucans of the fungal cell wall, and (3) GPI-anchored to the membrane.

Besides the polysaccharides described above that are covalently interlinked to form a skeletal structure, $\mathrm{N}$ - and $\mathrm{O}$-linked peptidogalactomannans were present in the outer layer of $A$. fumigatus cell wall and isolated by hot buffered aqueous extraction (Haido et al., 1998). O-linked oligosaccharides were selectively released from pGM by $\beta$-elimination under mild alkaline reductive conditions in the presence of sodium borohydride. Their primary structures were determined based on a combination of techniques including gas chromatography, ESI-QTOF-(Quadrupole followed by a time-of-flight mass analyzer) MS, ${ }^{1} \mathrm{H}$ - and TOCSY, and ${ }^{1} \mathrm{H}_{-}{ }^{13} \mathrm{C}$ HMQC NMR spectroscopy and methylation analysis, to be: $\alpha$-Glcp- $(1 \rightarrow 6)$-Man-ol, $\beta$-Gal $f-(1 \rightarrow 6)-\alpha$-Man $p-(1 \rightarrow$ 6)-Man-ol, $\beta$-Galf-(1 $\rightarrow 5)-\beta$-Gal $f-(1 \rightarrow 6)-\alpha-\operatorname{Man} p-(1 \rightarrow 6)$ Man-ol and $\beta$-Gal $f-(1 \rightarrow 5)-[\beta-G a l f-(1 \rightarrow 5)]_{3}-\beta$-Gal $f-(1 \rightarrow 6)$ Man-ol (Leitao et al., 2003). These $O$-linked oligosaccharides may account for a significant part of the peptidogalactomannan antigenicity, because de-O-glycosylation decreased by $50 \%$ its activity. The immunodominant epitopes were present in the tetra- and hexasaccharide, which contain a $\beta$-Gal $f-(1 \rightarrow 5)-\beta$-Gal $f$ terminal group (Leitao et al., 2003).

Another cell wall polysaccharide, a phosphonogalactomannan, was isolated via alkaline extraction from $A$. versicolor mycelia and its complex structure was identified by ${ }^{31} \mathrm{P},{ }^{1} \mathrm{H}$, and ${ }^{13} \mathrm{C} \mathrm{NMR}$ spectroscopy and methylation analysis and appeared to have similar structure as the galactomannan from A. fumigatus and A. niger, except for the presence of phosphorodiester groups (Tischer et al., 2002).

Galactomannans are major antigens produced during the infections caused by A. fumigatus. Galactomannans are detected in the serum and bronchoalveolar lavage of patients with invasive aspergillosis, and their detection has been used as a diagnostic marker for the infections caused by Aspergillus spp (Acosta et al., 2011; He et al., 2012; Teering et al., 2014). Galactomannans are secreted by A. fumigatus and, in association with galactosaminogalactans, are major components of the biofilm produced by the A. fumigatus mycelium. Interestingly, the A. fumigatus biofilm is found around the mycelia in aspergilomas and pulmonary lesions found in invasive infections, indicating that this structure must participate in the pathogenesis of the infections (Loussert et al., 2010). Galactomannans are able to inhibit the A. fumigatus conidial phagocytosis by dendritic cells, indicating that the recognition of cell surface expressed galactomannans is required for the A. fumigatus binding and internalization (Serrano-Gómez et al., 2004). Thus, glycoconjugates containing galactomannans must represent important antigens and targets for the immune 
response, besides playing a role in the pathogenesis of aspergillosis, possibly acting as components of extracellular adhesive structures during the host tissue colonization.

\section{$\alpha$-D-LINKED GLUCANS}

Another important group of polysaccharides, the $\alpha$-glucans, have been isolated from several fungal cells. The fungal $\alpha$ glucans described include $\alpha(1 \rightarrow 3)$-linked, and in some species glycogen-like $\alpha(1 \rightarrow 4)$ and $(1 \rightarrow 6)$-linked chains. The fungal $\alpha$ glucans described show an outermost localization in the cell wall and are easily extracted by hot extraction, being soluble in alkaline conditions, in opposition to the largely insoluble $\beta$-glucans that form the rigid core of the cell wall.

Pseudonigeran, isolated following alkaline extraction of cell walls of $A$. niger, is an $\alpha(1 \rightarrow 3)$-linked $\alpha$-D-glucopyranan as shown by methylation, periodate oxidation, and partial hydrolysis studies (Horisberger et al., 1972). It is also present in cell walls of A. nidulans, A. fumigatus, and Cryptococcus spp (Bacon et al., 1968; Zonneveld, 1972). An $\alpha(1 \rightarrow 3)$-glucan is present in the outer most layer of the Histoplasma capsulatum yeast cell wall (Rappleye et al., 2007), whereas the mycelial form contains none (Kanetsuna et al., 1974). In Blastomyces dermatiditis and Paracocciodioides brasiliensis the levels of the $\alpha(1 \rightarrow 3)$-glucans are much higher in the yeast than in the mycelial form (Kanetsuna and Carbonell, 1970, 1971; Kanetsuna et al., 1972). Another $\alpha$ glucan has been isolated from $P$. boydii and its structure was determined, using a combination of techniques including gas chromatography, ${ }^{1} \mathrm{H}$ TOCSY, ${ }^{1} \mathrm{H}$, and ${ }^{13} \mathrm{C}$ NMR spectroscopy and methylation analysis, to be a glycogen-like polysaccharide consisting of linear 4-linked $\alpha-\mathrm{D}-\mathrm{Gl} c p$ residues substituted at position 6 with $\alpha$-D-Glcp branches (Bittencourt et al., 2006). A similar structure was detected in A. fumigatus (Bahia et al., 1997).

The role of $\alpha$-glucans in the fungal biology is still incompletely understood. During the germination of A. fumigatus conidia, the exposure of $\alpha(1 \rightarrow 3)$-glucans promotes the aggregation and development of the germ tubes (Fontaine et al., 2010). In $H$. capsulatum, $\alpha(1 \rightarrow 3)$ glucans mask the $\beta(1 \rightarrow 3)$ glucans what results in a deficient recognition of these molecules by Dectin-1, and this has been speculated to avoid the induction of pro-inflammatory cytokines by macrophages (Rappleye et al., 2007). Glycogen-like $\alpha$-glucans isolated of $P$. boydii are able to inhibit the phagocytosis of $P$. boydii conidia, furthermore these molecules induce the release of pro-inflammatory cytokines by murine macrophages, thus indicating that $\alpha(1 \rightarrow 4)(1 \rightarrow 6)$ glucans represent immunostimulatory molecules mediating the recognition of $P$. boydii by macrophages (Bittencourt et al., 2006). Thus, the investigation of the roles of $\alpha$-glucans in the fungal development and interaction with immune cells must bring important insights in the fungal biology and virulence.

\section{$\beta$-D-LINKED GLUCANS}

$\beta$-D-Glucans are on interest because of their potential in modulating a wide range of innate host immune responses. They are present in virtually all fungi. A number of studies carried out on fungal polysaccharides have been demonstrating the presence of predominant 3-linked $\beta$-D-glucopyranosyl structures. A linear cell wall glucan from S. schenckii contains 3-O-, 6-O-, and
4-O-substituted $\beta$-D-glucopyranosyl units (Previato et al., 1979). Cell-wall polysaccharides, such as $\beta(1 \rightarrow 3)$-glucans, have been characterized in Aspergillus spp (Bernard and Latgé, 2001). The $\beta$ $D$-glucopyranan from the mycelial form of $P$. brasiliensis contains $90 \%$ of $(1 \rightarrow 3)$ linkages. This polymer is a major constituent of the cell wall of the filamentous phase of H. capsulatum (Davis et al., 1977). The $\beta$-D-glucopyranans of C. albicans serotype B and C. parapsilosis are mainly linear, with only approximately $10 \%$ of branch points, and contain, principally, $(1 \rightarrow 6)$ linkages $(67$ and 63\%, respectively) (Yu et al., 1967). C. albicans does not contain $\alpha$-glucans. It only contains both $\beta-1,3$ and $\beta$-1,6-glucans, but no mixed intrachain $\beta-1,3 / 1,6$ linkages. Analysis by proton NMR spectroscopy (NMR) of glucans from yeast or hyphal forms of C. albicans showed that they were different from S. cerevisiae glucans in side-chain branching and reducing termini (Ruiz-Herrera et al., 2006).

In a recent work, Lowman et al. (2014) using a mild extraction procedure for isolation of Candida albicans yeast and hyphal forms showed by NMR and GC-MS analysis that the hyphal glucan has a unique cyclic structure, not found in yeast glucan. Both are branched glucans having a $(1 \rightarrow 3)$-linked, $\beta$-Dglucopyranosyl main-chain, partially substituted at $O-6$ by ( single unit) $\beta$-D-glucopyranosyl groups. However, in addition to these linkages, a 2,3 linkage was identified and this feature has not been reported previously in C. albicans (Lowman et al., 2014). Interestingly, the cyclic hyphal $\beta$-glucan presents a differential pattern of cytokine induction by human monocytes in relation to that promoted by linear yeast $\beta$-glucans, with cyclic $\beta$-glucans being a more potent inducer of IL- $1 \beta$, TNF, and IL- 6 than the linear yeast $\beta$-glucans. As observed for the linear $\beta(1 \rightarrow 3)$ glucans the cyclic hyphal $\beta$-glucans are recognized by Dectin-1 (Lowman et al., 2014).

Fungal $\beta$-glucans have been recognized for so long as immunomodulators (Goodridge et al., 2009b). Large $\beta$-glucan particles induce cytokine production, reactive oxygen species (ROS) production and phagocytosis by neutrophils and macrophages, while soluble $\beta$-glucans act as antagonists of these responses (Brown and Gordon, 2001; Brown et al., 2003; Gantner et al., 2003; Kennedy et al., 2007; Goodridge et al., 2011). Furthermore, $\beta$-glucans induce the activation of the alternative pathway of the complement cascade (Bose et al., 2013). $\beta$-glucans are also efficient adjuvants, promoting dendritic cell maturation and antigen loading by these cells, what triggers the activation of CD4 and cross-priming of CD8 lymphocytes (Yoshitomi et al., 2005; Leibundgut-Landmann et al., 2008; Weck et al., 2008).

Recognition of fungal $\beta$-glucans by macrophages requires the exposure of the inner layer of the fungal cell wall, as a result of the growth or germination, as observed during division and septation of $C$. albicans yeasts and hyphae, and germination of resting conidia of A. fumigatus (Gantner et al., 2005; Hohl et al., 2005; Steele et al., 2005; Gersuk et al., 2006). Thus, the $\beta$-glucan recognition must represent a mechanism for the detection of the growth and morphological differentiation of pathogenic fungi. Interestingly, A. fumigatus and other environmental fungi express a highly hydrophobic external layer formed by hydrophobin proteins which masks the $\beta$-glucans in the resting conidia, and it has been speculated that the recognition of exposed $\beta$-glucans 
in the germinating conidia, but not in the resting ones, could have evolved to avoid the persistent inflammation, to the ubiquitous resting conidia, while permitting the detection of the invasive morphological stages (germ tubes and hyphae) (Aimanianda et al., 2009).

\section{CHITIN}

Chitin is an important skeletal component in most fungi. Chitin is a linear polysaccharide composed by 4-linked-2-acetamido-2deoxy- $\beta$-D-glucopyranan (Munro and Gow, 2001). Chitin and $\beta$-glucans are the most abundant polysaccharides conserved through the evolution in the fungal cell wall and are the most common polysaccharides in fungal species. Chitin represents a small percentage in S. cerevisiae, but the content is higher in other yeasts and filamentous fungi (Xie and Lipke, 2010). Chitin composes the insoluble core of the fungal cell wall, either isolated or associated with $\beta$-glucans (Masuoka, 2004). The composition of the alkali insoluble core of the A. fumigatus cell wall has been described, and it contains pure chitin chains, as well as chitin chains associated to $\beta-1,3$ glucans and chitin/galactomannans associated to the side branching chains of $\beta-1,3$ glucans (Fontaine et al., 2000).

Chitin and chitosan, its deacetylated polymer, present several immunomodulatory effects. Exposition to chitin has been implicated in the development of allergic airway inflammation, and in an experimental model of pulmonary inflammation induced by Aspergillus cell wall, the digestion with chitinase, decreases the inflammation, and leukocyte recruitment (Van Dyken et al., 2011). Chitin induces cytokine production, leukocyte recruitment, and alternative activation of macrophages (Reese et al., 2007; Da Silva et al., 2009, 2010). Furthermore, macrophages promptly ingest chitin and chitosan particles (Nishiyama et al., 2006). Curiously, chitosan, but not chitin, is able to promote the activation of the inflammasome NLRP3/ASC/caspase-1, and therefore chitosan leads to the activation of caspase- 1 and release of IL-1ß (Bueter et al., 2011, 2014).

\section{GALACTOSAMINOGALACTAN}

Galactosamine-containing polysaccharides have been identified in Aspergillus species. An exocellular polysaccharide from A. nidulans is a linear molecule and according to methylation analysis contains 4-O-substituted $\alpha$-D-galactopyranosyl and 4-O-substituted 2-acetamido-2-deoxy- $\alpha$-D-galactopyranosyl units. Periodate oxidation and ${ }^{1} \mathrm{H}-\mathrm{NMR}$ data showed their ratio to be approximately 1.8:1.0. (Gorin and Eveleigh, 1970). A heteropolysaccharide from $A$. niger has a related structure but lacks $N$-acetyl groups. It contains 4 -O-substituted $\alpha$ D-galactopyranosyl and 2-amino-2-deoxy- $\alpha$-D-galactopyranosyl units in the ratio 7:2 (Bardalaye and Nordin, 1976, 1977). A galactosaminogalactan secreted by the mycelium of A. fumigatus was identified and the carbohydrate structure analysis showed that it is a linear heterogeneous polymer of $\alpha-1-4$ galactosyl and $\alpha 1-4 N$-acetylgalactosaminyl residues (Fontaine et al., 2011). Galactosaminogalactans have been localized on the outer layer of the A. fumigatus cell wall and due to its localization might mask the exposure of other polysaccharides such as $\beta-(1 \rightarrow 3)$ glucan (Gravelat et al., 2013). In vitro studies suggest that this molecule is the principal mediator of $A$. fumigatus adherence and plays a role in biofilm formation (Loussert et al., 2010; Gravelat et al., 2013). The A. fumigatus galactosaminogalactans are antigenic, and anti-galactosaminogalactans antibodies are present in the human serum, even in the absence of Aspergillus spp infections, but these polysaccharides are in fact immunosuppressive, as observed by decreased neutrophil recruitment, and higher fungal loads, during the A. fumigatus experimental infection following the immunization with galactosaminogalactans (Fontaine et al., 2011). The immunosuppressive properties of A. fumigatus galactosaminogalactans have been attributed to the inhibition of the production of IFN- $\gamma$, neutrophil chemoattractant chemokines, and the induction of IL-1Ra, an antagonist cytokine for the IL-1 receptor (Gresnigt et al., 2014).

\section{PATTERN RECOGNITION RECEPTORS INVOLVED IN THE RECOGNITION OF FUNGAL CARBOHYDRATES TOLL LIKE RECEPTORS (TLRs)}

TLRs comprise a family of receptors that share homology with the Toll receptor (Takeuchi and Akira, 2010). The Drosophila Toll was described as a regulator of the dorsoventral differentiation in the embryo of Drosophila, and further pointed as a receptor required for the antifungal immune responses in Drosophila (Lemaitre et al., 1996). Following the characterization of the Toll receptor in Drosophila, 10 human TLRs, and 13 murine TLRs have been described (Takeuchi and Akira, 2010; Hidmark et al., 2012; Li and Chen, 2012; Oldenburg et al., 2012). TLRs present an amino-terminal extracellular domain containing leucine rich repeats and intracellular domains that share homology with the Toll/IL-1 receptor (TIR) domain. The TIR domains recruit adaptor proteins containing TIR domains, such as MyD88, TRIF, TRAM, and TIRAP, what leads to signaling pathways that culminate in the activation of the transcriptional complexes NF- $\kappa \mathrm{B}$, AP-1, IRFs (IRF3/7), and MAP kinases, and as consequence in the expression of cytokines and co-stimulatory molecules (Takeuchi and Akira, 2010).

TLR4 is the receptor responsible for responses to the bacterial lipopolysaccharides (LPS) (Poltorak et al., 1998). The LPS recognition by TLR4 requires the association with MD2 (Shimazu et al., 1999; Schromm et al., 2001; Akashi et al., 2003). TLR4 has been demonstrated to recognize fungal mannans. S. cerevisiae and C. albicans derived mannans induce cytokine production by human monocytes by a mechanism dependent on CD14, TLR4 and this is amplified in the presence of the Lipopolysaccharide Binding Protein (LBP) (Tada et al., 2002). Netea et al. reported, in an extensive investigation of mannosylation-defective $C$. albicans strains, that TLR4 cooperates with the Mannose Receptor (MR) in the recognition of mannans, with TLR4 detecting O-linked mannans, while MR is responsible for the sensing of $N$-linked mannans (Netea et al., 2006). TLR4 is also involved in the recognition of PRMs isolated from P. boydii (Figueiredo et al., 2010) and in detection of the glucuronoxylomannans from $C$. neoformans (Shoham et al., 2001), indicating that TLR4 acts as a receptor for the sensing of distinct mannose containing polysaccharides.

TLR2 recognizes bacterial lipoproteins and lipoteichoic acid, mycobacterial lipoarabinomannans, and GPI anchors from protozoan parasites (Takeuchi et al., 2000; Campos et al., 2001; 
Sandor et al., 2003; Tapping and Tobias, 2003; Krishnegowda et al., 2005). The recognition mediated by TLR2 have been described to involve the dimerization with TLR1, for the detection of triacylated lipoproteins (Takeuchi et al., 2002; Jin et al., 2007), or TLR6, in case of diacylated lipoproteins (Takeuchi et al., 2001; Kang et al., 2009).

TLR2 has also been pointed as a receptor involved in the recognition of fungal molecules. TLR2 is the receptor responsible for the activation of NF- $\kappa \mathrm{B}$ and cytokine release by macrophages in response to a PLM isolated from $C$. albicans, while TLR4 and TLR6 contribute partially to the responses evoked by this lipoglycan (Jouault et al., 2003). TLR2 has also been described as a receptor involved in the recognition of glucogen-like $\alpha$ 1,6-branched $\alpha$-1,4-glucans, such as an enzymatically produced glycogen (Kakutani et al., 2012), and a glycogen-like $\alpha$-glucan purified from $P$. boydii (Bittencourt et al., 2006). TLR2/TLR1 and TLR2/TLR6 is also involved in the recognition of the glucuronoxylomannans isolated from C. neoformans and C. gatii capsules (Fonseca et al., 2010).

The mechanisms by which TLR4 and TLR2 recognize mannose-containing glycoconjugates and other fungal polysaccharides are poorly understood. TLR4 and TLR2 have been demonstrated to bind fungal polysaccharides, and these interactions are inhibited in the presence of soluble mannans and fucose (Hsu et al., 2009). Mannans occur as polysaccharide components in the structures of many fungal glycoconjugates, such as glycoproteins and glycolipids (Masuoka, 2004). In this way, the widely employed mannan preparations are in fact highly heterogeneous mixtures of mannosylated glycoproteins, and possibly glycolipids. Thus, the use of purified mannans, as activators, ligands or competitors for TLR4 or TLR2 mediated responses, although useful in demonstrating the recognition of these fungal glycoconjugates, fails in elucidating the specific structural motifs involved in the activation of these receptors.

The structural bases for the recognition of bacterial lipoproteins and LPS, by TLR2/TLR1 and TLR2/TLR6, and TLR4/MD2, respectively, have been elucidated by crystallographic analyses (Jin et al., 2007; Kang et al., 2009; Park et al., 2009). The emerging pattern indicates that fatty acid chains in the bacterial ligands interact with hydrophobic pockets in the extracellular domain localized in the interfaces of the receptor complexes. It is unclear how TLR2 and TLR4 recognize hydrophilic ligands such as polysaccharides, but it seems reasonable that the interaction of these receptors with carbohydrates must work in a distinct way from the classical bacterial lipid ligands. In this sense, the role of TLR2 and TLR4 as receptors have been extensively expanded to the recognition of several distinct molecules, including heme (Figueiredo et al., 2007), hyaluronic acid (Termeer et al., 2002; Jiang et al., 2005; Scheibner et al., 2006), heparan sulfate (Johnson et al., 2002; Brunn et al., 2005) and biglycan (Schaefer et al., 2005). Thus, the mechanisms of recognition by these receptors seem to be wider than the previously described recognition of microbial lipid molecules.

In conclusion, it seems evident that more detailed investigations are required for the characterization of the mechanisms involved in the recognition of fungal carbohydrates by TLR2 and TLR4. Alternative approaches such as, (1) use of chemically defined oligosaccharides as ligands for TLR2 and TLR4, (2) specific enzymatic digestion of fungal polysaccharide preparations and analysis of TLR2 and TLR4 activation/binding, (3) extensive purification and elucidation of the structures of fungal polysaccharides by complementary analytic tools (mass spectrometry, RMN) and co-relation with TLR2 and TLR4 activation, and (4) TLR2 and TLR4 binding assays must be determinant for the elucidation of the recognition of fungal polysaccharides by TLR2 and TLR4.

\section{C-TYPE LECTIN RECEPTORS (CLR)}

CLR comprise an important group of proteins involved in the recognition of fungal pathogens. CLR are defined by the presence of domains composed by two loops joined by disulfide bonds, the C-type Lectin Domains (CTLDs), which contain carbohydrate recognition domains (CRD). CLR are characterized by the interaction with carbohydrates that in many cases requires the presence of $\mathrm{Ca}^{+2}$ (Sancho and Reis E Sousa, 2012). Two conserved motifs are present in the CRD and dictate the specificity for carbohydrates; the EPN motif confers binding to mannose, $N$-acetylglucosamine, L-fucose, and glucose, while a QPD motif determines the recognition of galactose and $\mathrm{N}$ acetylgalactosamine (Drickamer, 1992; Kolatkar and Weis, 1996; Kolatkar et al., 1998; Zelensky and Gready, 2005; Lee et al., 2011; Sancho and Reis E Sousa, 2012).

Among the CLRs, Dectin-1, Dectin-2, MCL, Mincle, MR, and DC-specific ICAM3-grabbing non-integrin (DC-SIGN) have been implied in the recognition of fungal carbohydrates (Sancho and Reis E Sousa, 2012; Zhu et al., 2013). Dectin-1, Dectin-2, MCL, and Mincle employ the Immunoreceptor Tyrosine-based Activation Motifs (ITAM) to induce cell signaling through the activation of Src kinases, Syk, and PLC $\gamma$ what leads to NF- $\kappa$ B and NFAT mediated transcription. Dectin-1 presents an intracellular tyrosine based motif named hemi-ITAM, since it presents only a LXXY, while a typical ITAM motif carries two similar separated tyrosine based motifs (YXXL/I). Dectin-2, Mincle, and MCL do not bear ITAM motifs, but they signal through the interaction with the ITAM containing protein, FcR $\gamma$ chain. MR and DCSIGN do not present ITAM motifs, although they are involved in the modulation of cytokine production by macrophages and dendritic cells and in the internalization of carbohydrate-carrying molecules and pathogens (Sancho and Reis E Sousa, 2012).

\section{MANNOSE RECEPTOR (CD206)}

$\mathrm{MR}$ is a type-I transmembrane protein presenting an $N$-terminal cysteine rich domain, a fibronectin type II domain, eight extracellular CTLDs (1-8), and an intracellular portion that contains a motif involved in the endocytic signaling, FENTLY (MartinezPomares, 2012). MR recognizes glycoconjugates containing mannose, fucose, $\mathrm{N}$-acetylglucosamine (Taylor et al., 1992; Taylor and Drickamer, 1993), sulfated $N$-acetylgalactosamine or sulfated galactose (Leteux et al., 2000; Liu et al., 2000). Recognition of sulfated polysaccharides is dependent on the cysteine-rich domain, but is independent of the CLTDs (Leteux et al., 2000; Liu et al., 2000). In contrast, recognition of mannose containing glycoconjugates requires the activity of the CTLDs $4-8$, as demonstrated 
by binding assays employing recombinant versions of the MR CTLDs (Taylor et al., 1992).

$\mathrm{MR}$ is involved in the recognition of several fungal pathogens, such as Pneumocystis carinii and C. albicans (Ezekowitz et al., 1991; Netea et al., 2006; Cambi et al., 2008). MR has been described as a receptor involved in the phagocytosis of fungal pathogens (Ezekowitz et al., 1991; Cambi et al., 2008), but its role as a professional phagocytic receptor has been questioned when MR is expressed in non-phagocytic cells (Le Cabec et al., 2005). Although the ability of MR in triggering phagocytic signaling pathways has been put in check, it is well-established that MR promotes the endocytosis of mannose-containing ligands and participates in the phagocytosis of fungal pathogens (Ezekowitz et al., 1991; Burgdorf et al., 2006; Cambi et al., 2008). Thus, it is possible that MR acts as a receptor involved in the binding of mannose containing ligands what would permit the internalization mediated by another phagocytic receptor. Alternatively the phagocytic activity of MR must be a cell type specific property.

$\mathrm{MR}$ is also involved in the induction of signaling pathways that promote cytokine production in response to fungal pathogens and mannans (Netea et al., 2006; Tachado et al., 2007; Van De Veerdonk et al., 2009). TNF release by macrophages in response to $C$. albicans requires the recognition mediated by $\mathrm{MR}$ and TLR4 for $N$-linked mannans and $O$-linked mannans, respectively (Netea et al., 2006). MR has been demonstrated to recognize mannosylated glycoconjugates, such as phosphatydil-myo-inositol mannosides (PIMs) and mannose-capped lipoarabinomannan (LAM) from mycobacteria, and $O$-linked recombinant proteins expressed in Pichia pastoris. Thus, while $N$-linked mannoproteins seems to be the major ligands for MR in C. albicans, it is possible that other mannosylated glycoconjugates could be recognized by MR in fungal pathogens (Kang et al., 2005; Torrelles et al., 2006; Lam et al., 2007). MR cooperates with TLR2 in the induction of cytokines in response to $P$. jirovecci, and upon the $P$. jirovecci stimulation these receptors physically interact (Tachado et al., 2007). How MR contributes to signaling pathways involved in cytokine production is still unknown. MR has been described to promote the $\operatorname{PPAR}_{\gamma}$ expression and activation and this pathway is required for the induction of cytokines by mycobacterial ManLAM (Rajaram et al., 2010). However, MR has a short intracellular domain that lacks known signaling motifs involved in the gene expression of cytokines. Thus, it seems probable that MR works in cooperation with other receptors which are able to trigger the expression of cytokines, such as TLRs and CLRs.

\section{DECTIN-2}

Dectin-2 was initially characterized as a CLR expressed in a cell line derived from Langerhans cells. Dectin-2 is a type II transmembrane protein with one CLTD present in the $\mathrm{COOH}$ terminal region and a short cytoplasmic tail. Dectin-2 activation is able to induce the production of cytokines and eicosanoids (Sato et al., 2006; Barrett et al., 2009; Saijo et al., 2010). Dectin-2 is expressed in macrophages, some populations of dendritic cells and in IL-6/IL-23 stimulated neutrophils (Ariizumi et al., 2000a; Taylor et al., 2005, 2014; Barrett et al., 2009; Robinson et al., 2009).
Dectin-2 has been described to recognize $\alpha$-mannans (Saijo et al., 2010). Dectin-2 has an EPN motif in the extracellular domain, which has been demonstrated to be involved in the binding to mannose/fucose containing glycoconjugates (Ariizumi et al., 2000a). Dectin-2 binds to zymosan in a $\mathrm{Ca}^{+2}$ dependent mechanism that is inhibited by mannose, fucose, and in higher concentrations, $\mathrm{N}$-acetylglucosamine, glucose, and galactose. Dectin-2 binds efficiently to extensively mannosylated synthetic carbohydrates, such as $\mathrm{Man}_{9} \mathrm{GlcNac}_{2}$, while binding decreases deeply with the reduction in the mannose residues (McGreal et al., 2006). Binding assays have demonstrated the Dectin-2 binding to BSA conjugated to different monosaccharides. Dectin-2 shows maximal binding to mannosylated and fucosylated-BSA, while the binding to BSA conjugated to $\mathrm{N}$ acetylglucosamine, glucose or $N$-acetylgalactosamine is greatly reduced (Lee et al., 2011). Dectin-2 is a receptor involved in the recognition of Malassezia spp and C. albicans, and the Dectin-2 ligands have demonstrated to be a glycoprotein containing $O$ linked $\alpha$-1,2-mannobiose residues, for Malassezia (Ishikawa et al., 2013), and $\alpha$-mannans, for C. albicans (Saijo et al., 2010; Zhu et al., 2013).

Recently, Dectin-2 has been demonstrated to cooperate with MCL for the recognition of fungal mannans. Dectin-2 and MCL bind to mannans, and also form heterodimeric complexes. Although the expression of each receptor can promote the recognition of $C$. albicans hyphae and mannans, their association confers a higher sensitivity to the recognition of mannans and C. albicans (Zhu et al., 2013). Thus, the cooperation between MCL and Dectin-2 must represent a general mechanism of interaction of CLRs, extending and amplifying leukocyte responses to fungal carbohydrates.

\section{DECTIN-1}

Dectin-1 was first identified by means of the isolation of mRNA selectively expressed in a Langerhans cell derived line (Ariizumi et al., 2000b). Dectin-1 is a type II transmembrane protein and its structure comprises one CTLD in the extracellular portion, and a cytoplasmic region that presents the signaling motif, hemi-ITAM (Sancho and Reis E Sousa, 2012). Dectin1 is expressed in macrophages, dendritic cells, neutrophils, and eosinophils (Brown et al., 2002; Taylor et al., 2002; Willment et al., 2005). Dectin-1 mediated signaling promotes cytokine production (Brown et al., 2003; Rogers et al., 2005; Rosas et al., 2008; Goodridge et al., 2009a), generation of ROS (Gantner et al., 2003; Kennedy et al., 2007), phagocytosis (Brown and Gordon, 2001; Brown et al., 2002) and dendritic cell maturation (Yoshitomi et al., 2005). Thus, Dectin-1 acts as a PRR connecting the recognition of fungal exposed $\beta$-glucans to the leukocyte activation and adaptive immunity induction.

Differently from many CLRs, Dectin- 1 binding to $\beta$-glucans does not require $\mathrm{Ca}^{+2}$, although it occurs by means of the interaction of the extracellular CTLD with $\beta 1,3$-glucans (Brown and Gordon, 2001; Adams et al., 2008). Surface plasmon resonance binding assays have demonstrated that Dectin-1 shows an extraordinary specificity to $\beta 1,3$-glucans containing $\beta 1,6$ branches, in contrast Dectin-1 do not bind mannans, pullulans, $\beta 1,6$-glucans or $\beta 1,3 / \beta 1,4$-glucans (Adams et al., 2008). 
The minimal structure recognized by Dectin-1 is a $\beta 1,3$ heptasaccharide of glucose with a terminal $\beta 1,6$-glucose branch, and higher polymerization degrees increase the affinity of Dectin-1 by $\beta$ 1,3-glucose oligosaccharides (Adams et al., 2008).

The mechanism of activation of Dectin- 1 involves the clustering of the receptor by aggregates of $\beta$-glucans (Rosas et al., 2008; Goodridge et al., 2011). Although Dectin-1 shows a high affinity for soluble $\beta$-glucans, for example glucan phosphate presents an IC50 for the competition of the Dectin-1 binding to glucans of about 2 pmol L ${ }^{-1}$ (Adams et al., 2008), soluble $\beta$-glucans act as antagonists of the activation induced by $\beta$-glucan particles (Brown et al., 2003; Gantner et al., 2003). The activation of Dectin- 1 requires its own clustering by $\beta$-glucan particles and the exclusion of the tyrosine phosphatases CD45 and CD148. CD45 and CD148 play a dual role in the Dectin-1 signaling, promoting the basal activity of Src kinases through the remotion of an inhibitory phosphotyrosine, while upon the clustering of Dectin$1 / \beta$-glucan particles, they become excluded from the signaling cluster, what must permit the ITAM signaling pathway to proceed (Goodridge et al., 2011). Thus, the activation of Dectin-1 is regulated by the physical nature of its ligands, with $\beta$-glucan particles of $0.5 \mu \mathrm{m}$ or larger being strong activators of Dectin-1 (Goodridge et al., 2011).

Dectin-1 mediated responses are specific for some myeloid cells. Bone marrow derived macrophages and elicited peritoneal macrophages do not present Dectin-1 mediated responses, in contrast, alveolar macrophages, resident peritoneal macrophages and dendritic cells show Dectin-1 dependent responses to $\beta$ glucans (Rosas et al., 2008; Goodridge et al., 2009a). GM-CSF and IFN- $\gamma$ can promote Dectin-1 responsiveness to non-responding cells, such as bone marrow macrophages, indicating that the responses mediated by Dectin-1 are flexible, according the program of differentiation of myeloid cells (Rosas et al., 2008; Goodridge et al., 2009a).

\section{MINCLE}

Mincle was firstly identified as a macrophage expressed gene dependent on the activity of the transcriptional factor NF-IL6 (Matsumoto et al., 1999). Mincle is a type II transmembrane protein containing a short intracellular tail and a CLTD in the extracellular domain. Mincle induces cell signaling through the interaction with the FcR $\gamma$ chain which contains ITAM motifs and thus promotes Syk activation, and the NF- $\kappa \mathrm{B}$ and NFAT mediated transcription of cytokines (Yamasaki et al., 2008).

Mincle has been demonstrated to be involved in the fungal recognition (Bugarcic et al., 2008; Wells et al., 2008; Yamasaki et al., 2009). Soluble recombinant Mincle binds to C. albicans (Bugarcic et al., 2008). Mincle is required for the TNF production by macrophages in response to $C$. albicans and Clec $4 e^{-/-}$ mice show a deficient clearance of $C$. albicans in an experimental model of infection (Wells et al., 2008). Mincle also recognizes the human commensal fungi, Malassezia spp. Mincle is able to confer NFAT activation by cell lines in response to Malassezia spp, besides $\mathrm{Clec} 4 e^{-/}$macrophages shows impaired cytokine production in response to Malassezia spp stimulation. Supporting the in vitro data, Clec4 $e^{-/}$mice show impaired leukocyte recruitment and cytokine production in a model of peritonitis induced by Malassezia challenge (Yamasaki et al., 2009). Recently, Ishikawa et al. have demonstrated that two Malassezia derived glycolipids are ligands for Mincle, a glyceroglycolipid containing the disaccharide gentiobiose joined to a glycerol backbone, which is acylated with C14 and C18 fatty acids, and a polar glycolipid composed by two mannosyl-10-hydroxy-octadecanoic acids and one dimannosyl-10-hydroxy-octadecanoic acid which are esterified to a mannitol core (Ishikawa et al., 2013). Although the ligands for Mincle have not been identified in other fungi, it seems reasonable that Mincle must recognize fungal glycolipids in other fungal pathogens, for example C. albicans (Bugarcic et al., 2008; Wells et al., 2008).

\section{DC-SIGN (CD209)}

DC-SIGN is a type II transmembrane protein and its extracellular domain carries one CRD in the $\mathrm{COOH}$-terminal portion and seven repeats which form an extracellular stalk that has been implied in the oligomerization of DC-SIGN (Geijtenbeek et al., 2000; Mitchell et al., 2001). The DC-SIGN CRD presents an EPN motif, and as expected DC-SIGN binds mannose-containing glycoconjugates, as well fucosylated carbohydrates, such as Lewis antigens, in a $\mathrm{Ca}^{+2}$ dependent mechanism (Appelmelk et al., 2003; Guo et al., 2004). The intracellular amino-terminal domain bears motifs involved in the internalization, such as triacidic and di-leucine sequences and non-ITAM/ITIM tyrosine based motifs (Van Kooyk and Geijtenbeek, 2003). DC-SIGN is an endocytic receptor involved in the binding and internalization of many pathogens, and it is expressed by dendritic cells and macrophages (Kwon et al., 2002; Geijtenbeek et al., 2003; Tailleux et al., 2003; Tassaneetrithep et al., 2003), as well as mannosylated and fucosylated antigens (Appelmelk et al., 2003; Frison et al., 2003; Guo et al., 2004). Coherently with its role as an endocytic receptor, the DC-SIGN mediated binding is decreased in the low $\mathrm{pH}$ values found during endosomal acidification, what indicates that, upon internalization by DC-SIGN, the cargo is released in the endosomal vesicles (Guo et al., 2004). DCSIGN mediated recognition of mannose containing ligands has been described to amplify the cytokine production induced by TLR activation, while fucosylated ligands inhibit the induction of pro-inflammatory cytokines, but amplify the expression of IL-10 (Gringhuis et al., 2009). Furthermore, DC-SIGN activation by mannosylated lipoarabinomannans (ManLAM) has been demonstrated to inhibit the dendritic cell maturation by LPS (Geijtenbeek et al., 2003). Thus, DC-SIGN triggering has complex effects, promoting the entry of pathogens, inducing the production of cytokines, particularly IL-10, while inhibiting dendritic maturation, and it is speculated that DC-SIGN targeting by some pathogens could promote immune evasion during the infection of dendritic cells (Van Kooyk and Geijtenbeek, 2003).

DC-SIGN is involved in the fungal recognition. Expression of DC-SIGN in non-phagocytic cells is able to promote binding and phagocytosis of C. albicans. Besides, DC-SIGN is recruited to the dendritic cell phagosomes containing C. albicans, and its blockade decreases the $C$. albicans binding and internalization (Cambi et al., 2003, 2008). N-linked mannans have been described as the glycoconjugates responsible for C. albicans binding and internalization by dendritic cells, since a decreased 
binding of $C$. albicans is observed with deficient $N$-linked mannosylation strains (Cambi et al., 2008). In contrast, dendritic cells do not show any deficiency in the binding of $C$. albicans strains showing deficient $O$-linked mannosylation, lacking phosphomannans or terminal $\beta 1,2$-mannoses. Interestingly, DC-SIGN mediated binding of $C$. albicans requires $N$-linked mannans, while intact $O$-linked mannans, phosphomannans or terminal $\beta 1,2$ mannosides are dispensable. Although DC-SIGN is clearly involved in the recognition of $C$. albicans by dendritic cells, it cooperates with MR that makes the greatest contribution for the C. albicans binding to dendritic cells (Cambi et al., 2008). Altogether, these results indicate that MR and DC-SIGN mediate the recognition of $C$. albicans $N$-linked mannans promoting binding and internalization. DC-SIGN is also a receptor for the recognition of $A$. fumigatus conidia by human dendritic cells and macrophages. In contrast to C. albicans, DC-SIGN, but not $\mathrm{MR}$ receptor, is required for the binding of $A$. fumigatus conidia by human dendritic cells. A. fumigatus recognition by DC-SIGN is inhibited by purified mannans and galactomannans, and since $A$. fumigatus presents galactomannans as major mannose containing glycoconjugates, it must be an important target for DC-SIGN recognition by A. fumigatus (Serrano-Gómez et al., 2004).

The structural determinants for the DC-SIGN binding are the presence of terminal mannose or fucose residues. Binding assays have demonstrated that the soluble DC-SIGN CRD binds to mannans, mannose-containing oligosaccharides, and Lewis antigen structures, in a $\mathrm{Ca}^{+2}$ dependent mechanism (Appelmelk et al., 2003; Guo et al., 2004; Van Liempt et al., 2004). DCSIGN binding to mannosylated proteins is inhibited by soluble fucose- and mannose-conjugated proteins, and in a lower extension by glucose-conjugates, while $N$-acetylgalactosamine- and $\mathrm{N}$-acetylglucosamine-conjugates are ineffective as competitors (Lee et al., 2011). Crystallographic analyses demonstrate that mannose and fucose residues interact with the primary binding site in the CRD domain, in coordination with $\mathrm{Ca}^{+2}$ that interacts with two hydroxyl groups, while adjacent residues, such as galactose or mannose, present, respectively in high mannose containing structures, interact with secondary binding sites (Guo et al., 2004). Recognition of fucosylated Lewis structures requires strict interaction of a galactose with the secondary binding site, and the sialylation of the adjacent galactose abolishes the DC-SIGN binding to Lewis ${ }^{\mathrm{X}}$ and Lewis ${ }^{\mathrm{A}}$ ligands while sulfation reduces the binding (Appelmelk et al., 2003; Guo et al., 2004).

Although DC-SIGN has been pointed as a receptor involved in the binding and internalization of fungal pathogens, the roles of DC-SIGN in modulating dendritic cell and macrophage responses to fungi are still unknown. DC-SIGN has been implied in the induction of IL-10 and inhibition of dendritic cell maturation, so it would be interesting to evaluate the impact of DC-SIGN mediated recognition in the responses of dendritic cells and induction of $\mathrm{T}$ cell mediated responses to fungal pathogens. Alternatively, DC-SIGN could cooperate with other PRR, amplifying the pro-inflammatory induction in response to fungi, as previously observed with LAMs and TLR agonists.

\section{CD11b/CD18 (MAC-1, CR3)}

$\mathrm{CD} 11 \mathrm{~b} / \mathrm{CD} 18$ is a member of the leukocyte specific integrins that share the $\beta_{2}$ common chain, also identified as CD18. $\mathrm{CD} 11 \mathrm{~b} / \mathrm{CD} 18$ is a heterodimeric complex composed of the noncovalently associated type I proteins, the $\alpha \mathrm{M}$ chain (CD11b) and the common chain CD18. It is expressed by leukocytes, including neutrophils, monocytes, macrophages, eosinophils, and NK cells (Ross, 2000; Hynes, 2002).

Besides its roles as a mediator of the leukocyte adhesion to the activated endothelium and the phagocytic receptor for iC3b opsonized particles (Holers, 2014), CD11b/CD18 has also been described to recognize $\beta 1,3$-glucans. The $\alpha \mathrm{M}$ chain presents two distinct domains involved in the recognition of the ligands by $\mathrm{CD} 11 \mathrm{~b} / \mathrm{CD} 18$, the I-domain that is involved in the binding to $\mathrm{iC} 3 \mathrm{~b}, \mathrm{ICAM}-1$, and fibrinogen, while a distinct lectin domain has been implied in the recognition of $\beta 1,3$-glucans, $N$-acetyl- $D$-glucosamine, glucose, and mannose (Thornton et al., 1996).

CD11b/CD18 has been demonstrated to be the major receptor involved in the binding of zymosan and $S$. cerevisiae yeasts, as well as the ROS production by these stimuli, by human neutrophils and macrophages, while Dectin-1 was demonstrated to be dispensable for these responses (Van Bruggen et al., 2009). Otherwise, the cooperation of Dectin-1 and CD11b/CD18 is necessary for neutrophil responses to zymosan and $\beta$-glucans, while macrophage recognition of $\beta$-glucans relies only in the Dectin-1 mediated recognition (Li et al., 2011). This mechanism requires the inside-out activation of CD11b/CD18 by Dectin- 1 mediated recognition of $\beta$-glucans which promotes Vav1,3 activation and thus enables CD11b/CD18 binding and internalization of $\beta$-glucans by neutrophils, as well as ROS production (Li et al., 2011). In contrast with the recognition of $\beta$-glucan particles, the binding of soluble $\beta$-glucans by human monocytes and neutrophils has been demonstrated to be dependent on the $\beta$-glucan opsonization by iC3b which promotes CD11b/CD18 binding (Bose et al., 2013). Interestingly the responses of blood mononuclear cells to $\beta$-glucans particles requires the Dectin- 1 mediated recognition, while soluble $\beta$-glucans require the $\mathrm{CD} 11 \mathrm{~b} / \mathrm{CD} 18$ mediated detection (Bose et al., 2014). A similar role for Dectin1 recognition of $\beta$-glucan particles, in contrast to a role for the complement for soluble $\beta$-glucans, has been observed for the antitumoral responses induced by the treatment with these $\beta$-glucans in murine experimental models (Qi et al., 2011).

While CD11b/CD18 has been convincingly demonstrated to be a receptor for $\beta$-glucans, there is still a considerable controversy about its role in the recognition of $\beta$-glucans, and this seems to extend in some experimental settings to the Dectin-1 mediated responses. Differences in the experimental settings must be responsible for the observed disparities, including (1) use of distinct $\beta$-glucan structures (particulated vs. soluble) (Rosas et al., 2008; Qi et al., 2011; Bose et al., 2013), heterogeneity and purity of the $\beta$-glucan particles, since zymosan and fungi are in fact highly heterogeneous and contains mannans, as well as chitin and lipids, furthermore zymosan is also a TLR activator (Van Bruggen et al., 2009), (3) presence of serum (a source of C3 that may trigger CD11b/CD18 activation even in situations where $\beta$-glucans were not recognized) (Bose et al., 2013), and (4) differences in the 
cell types investigated (neutrophils vs. macrophages) (Qi et al., 2011). Thus, CD11b/CD18 and Dectin-1 are receptors involved in the recognition of $\beta$-glucans and their activities must dictate the outcome of immune responses during the fungal infections. Besides that, while CR3 has been demonstrated to recognize fungal $\beta$-glucans, it has also been described to be a receptor for the internalization of mycobacterial glycoconjugate-coated beads, such as mycobacterial PIM $_{2}$ or a succinylated glycopeptidolipid (Villeneuve et al., 2005). Thus, considering the ability that CR3 presents as a lectin receptor, it must also work as a receptor for fungal glycoconjugates other than $\beta$-glucans.

\section{CD14}

CD14 is a glycosylphosphatidylinositol (GPI) anchored membrane protein presenting an extracellular amino-terminal portion containing leucine rich repetitions that assume a horseshoe-like conformation carrying a large hydrophobic pocket (Kim et al., 2005; Kelley et al., 2013; Zanoni and Granucci, 2013). CD14 has been demonstrated to be a receptor for bacterial LPS, and although CD14 lacks an intracellular signaling region, it cooperates with the TLR4/MD2 complex, conferring a highly sensitive recognition of LPS (Akashi et al., 2003). CD14 has been also described to work as a co-receptor for the recognition mediated by TLR2 (Schröder et al., 2004), TLR3 (Lee et al., 2006), TLR7 and TLR9 (Baumann et al., 2010).
CD14 is also involved in the recognition of fungal carbohydrates and glycoconjugates. Recognition of C. albicans and $S$. cerevisiae mannans is dependent on CD14, LBP, and TLR4 which shows similarities with the LPS detection, thus suggesting that LBP mediates the transfer of soluble mannans to CD14 and TLR4 (Tada et al., 2002). CD14 has also been demonstrated to be required for the recognition of fungal $\alpha$-glucans (Bittencourt et al., 2006). Coherently with the observations of the CD14 mediated recognition of fungal carbohydrates, CD14 is also involved in the recognition of the fungi A. fumigatus (Wang et al., 2001; Mambula et al., 2002) and P. boydii (Figueiredo et al., 2010).

The structural bases of the CD14 interactions with fungal carbohydrates are still unknown. Crystallographic analyses of CD14 have revealed a $\mathrm{NH}_{2}$-terminal hydrophobic region buried in a horseshoe structure. Based on the proposed structure of CD14 and the structure of LPS, the large hydrophobic pocket seems to be site interacting with the lipid portion of LPS (Kim et al., 2005; Kelley et al., 2013). Otherwise, the hydrophilic O-antigen, a long and variable polysaccharide chain present in LPS, as well as peptidoglycan, have been described to interact with CD14 (Kitchens and Munford, 1995; Schwandner et al., 1999). The neighbor grooves and edges around the hydrophobic pocket are speculated to support hydrophilic interactions with polysaccharides (Kim et al., 2005; Kelley et al., 2013). Thus, although direct CD14 binding to mannans or $\alpha$-glucans has not been evaluated, CD14 must

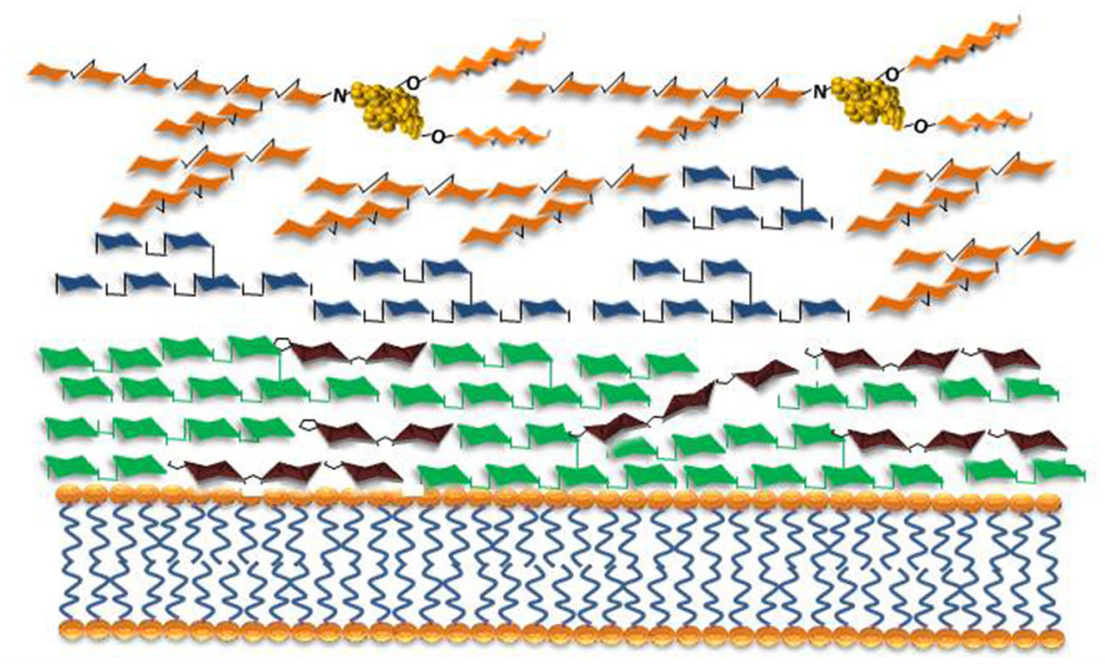

Cell wall

Cell membrane

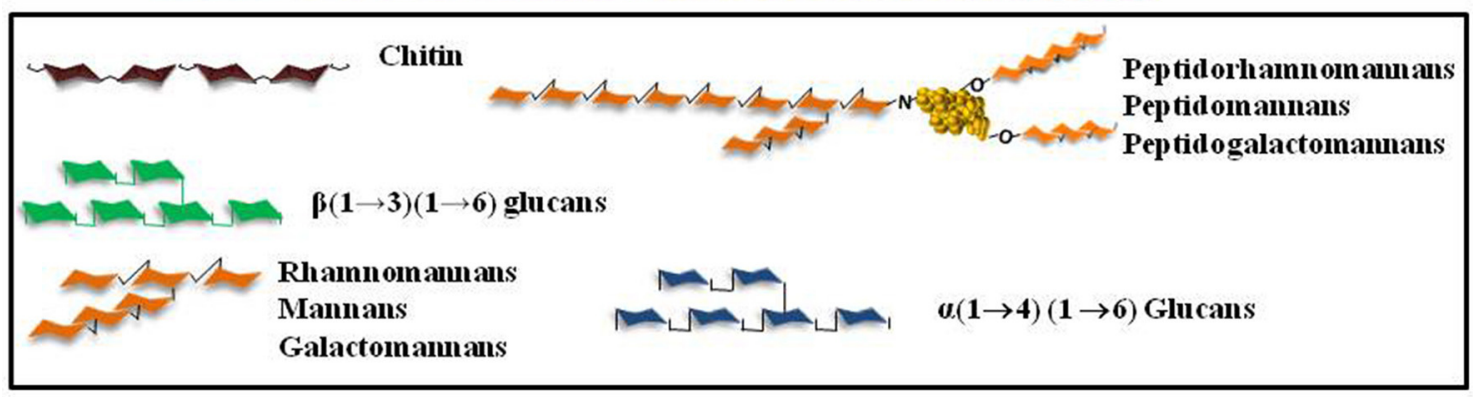

FIGURE 1 | Schematic representation of the major cell wall components of the fungi $A$. fumigatus, $C$. albicans, Scedosporium/Pseudallescheria complex. 
be able to bind fungal polysaccharides using hydrophilic clefts. Based on the role of CD14 for the recognition of TLR ligands, it is probable that CD14 must bind fungal polysaccharides and load them into TLR4 or TLR2, thus promoting the signaling by these receptors.

\section{THE RECOGNITION OF CHITIN, A PUZZLE INCLUDING SEVERAL CANDIDATES AND RESPONSES}

While chitin and chitosan are clearly recognized by leukocytes, there is still a great controversy about the mechanisms of recognition of chitin. Silva et al. have demonstrated that chitin induces cytokine production by macrophages by a mechanism involving the recognition mediated by TLR2, MR, and Dectin-1 (Da Silva et al., 2009). In contrast, other studies have failed to demonstrate that highly purified chitin particles can induce pro-inflammatory cytokine production by peripheral mononuclear blood cells (Mora-Montes et al., 2011). Instead, C. albicans purified chitin has been demonstrated to inhibit the C. albicans induced cytokine production by blood mononuclear leukocytes (Mora-Montes et al., 2011). Highly purified chitin particles induce IL-10 production by macrophages and this requires the TLR9, MR, and NOD2 mediated recognition (Wagener et al., 2014). Chitin is able to reduce the inflammatory cell recruitment induced the in vivo LPS challenge. Corroborating the anti-inflammatory properties of chitin particles, a chitin deficient $C$. albicans strain induces an increased TNF release, what is mimicked by the inhibition of chitinases during the stimulation with the wild-type C. albicans strain (Wagener et al., 2014).

Many questions remain about the chitin recognition by leukocytes. The commonly used commercial sources of chitin have been demonstrated to carry contaminants of glucose, mannose, and undefined molecules what may contribute for some responses, such as cytokine induction by macrophages (MoraMontes et al., 2011; Wagener et al., 2014). Furthermore, although macrophages are able to phagocytose chitin particles, the mechanisms involved are still unknown. The direct interaction of proposed receptors with chitin particles has also not been demonstrated. Even so TLR2 and TLR9 have been pointed as receptors for chitin induced cytokine release (Da Silva et al., 2009; Wagener et al., 2014), the eosinophil recruitment induced by chitin is MyD88 independent (Reese et al., 2007), thus excluding a role for TLR2 and TLR9 in the chitin induced eosinophilic inflammation. Besides, many aspects may influence the results obtained with chitin particles, such as (1) the presence of contaminants,

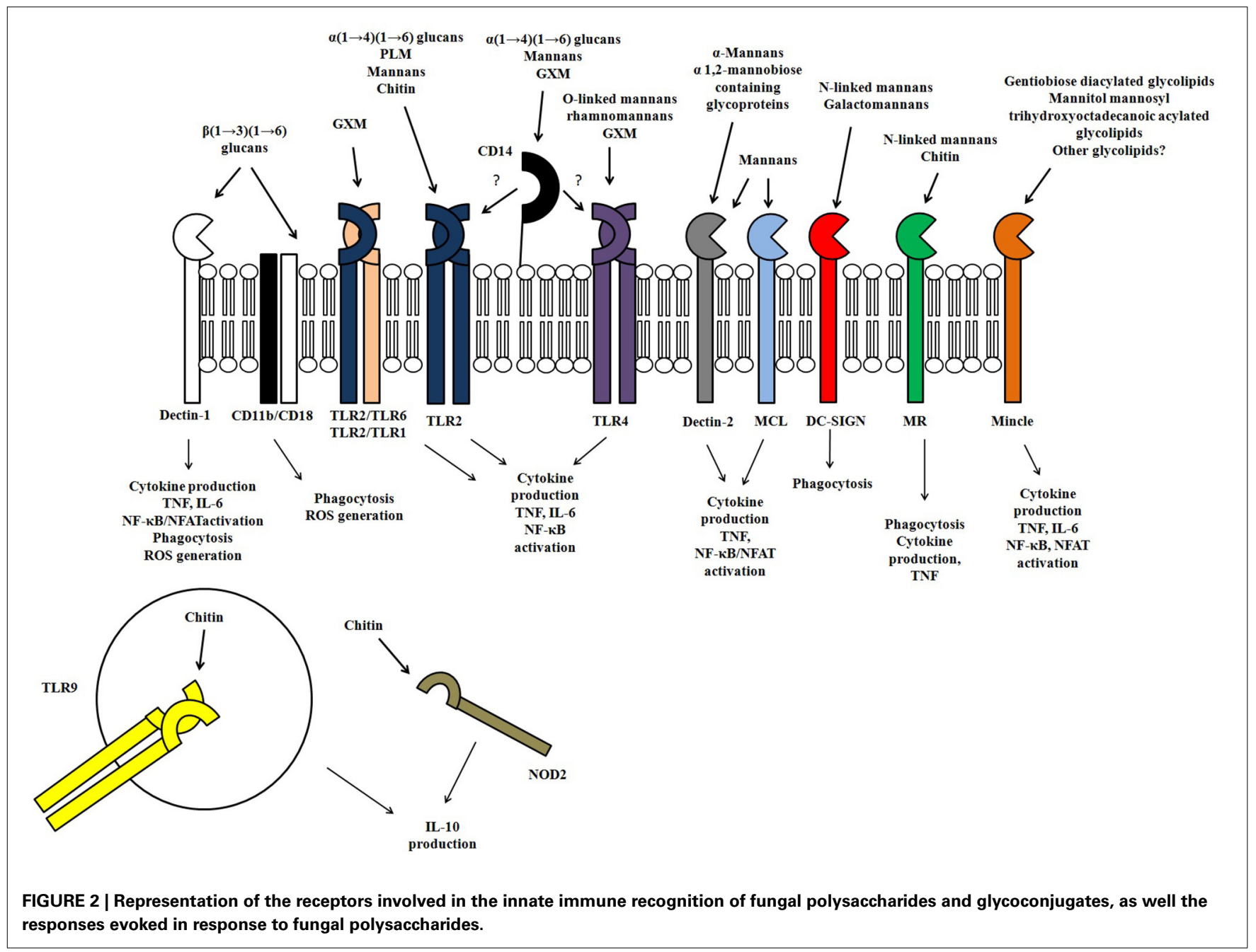


(2) responses to distinct cell types (blood mononuclear cells, peritoneal macrophages, macrophage cell lines), (3) size and acetylation of chitin particles. Thus, although chitin represents a target for the innate immune recognition, more extensive analyses are required to characterize the immune responses to chitin and the receptors involved.

\section{CONCLUSIONS}

Polysaccharides and glycoconjugates are the major components of the fungal surface. Their structures vary among filamentous fungi and yeast and also among fungal species (Figure 1). The variety of carbohydrate structures present in the different fungal pathogens offers exceptional targets for the innate immune recognition which has evolved to recognize specific fungal glycans through a plethora of different receptors (Figure 2). Thus, the identification of fungal carbohydrates and their recognition by pattern recognition receptors must bring important contributions to the comprehension of the pathogenesis and immunity to fungal infections, and this must reveal new opportunities for the development of new classes of immunomodulators, antigens, and adjuvants.

\section{ACKNOWLEDGMENTS}

The authors like to thank Dr. Vera C. B. Bittencourt for contributing for this review with Figure 1. This work was supported by Conselho Nacional de Desenvolvimento Científico e Tecnológico $(\mathrm{CNPq})$, Fundação de Amparo à Pesquisa no Estado do Rio de Janeiro (FAPERJ), Coordenação de Aperfeiçoamento Pessoal de Nível Superior (CAPES_PROEX) and Universidade Federal do Rio de Janeiro (UFRJ).

\section{REFERENCES}

Acosta, J., Catalan, M., Del Palacio-Peréz-Medel, A., Lora, D., Montejo, J. C., Cuetara, M. S., et al. (2011). A prospective comparison of galactomannan in bronchoalveolar lavage fluid for the diagnosis of pulmonary invasive aspergillosis in medical patients under intensive care: comparison with the diagnostic performance of galactomannan and of $(1 \rightarrow 3)-\beta$-d-glucan chromogenic assay in serum samples. Clin. Microbiol. Infect. 17, 1053-1060. doi: 10.1111/j.14690691.2010.03357.x

Adams, E. L., Rice, P. J., Graves, B., Ensley, H. E., Yu, H., Brown, G. D., et al. (2008). Differential high-affinity interaction of dectin-1 with natural or synthetic glucans is dependent upon primary structure and is influenced by polymer chain length and side-chain branching. J. Pharmacol. Exp. Ther. 325, 115-123. doi: 10.1124/jpet.107.133124

Aimanianda, V., Bayry, J., Bozza, S., Kniemeyer, O., Perruccio, K., Elluru, S. R., et al. (2009). Surface hydrophobin prevents immune recognition of airborne fungal spores. Nature 460, 1117-1121. doi: 10.1038/nature08264

Akashi, S., Saitoh, S., Wakabayashi, Y., Kikuchi, T., Takamura, N., Nagai, Y., et al. (2003). Lipopolysaccharide interaction with cell surface Toll-like receptor 4-MD-2: higher affinity than that with MD-2 or CD14. J. Exp. Med. 198, 1035-1042. doi: 10.1084/jem.20031076

Appelmelk, B. J., Van Die, I., Van Vliet, S. J., Vandenbroucke-Grauls, C. M., Geijtenbeek, T. B., and Van Kooyk, Y. (2003). Cutting edge: carbohydrate profiling identifies new pathogens that interact with dendritic cell-specific ICAM-3-grabbing nonintegrin on dendritic cells. J. Immunol. 170, 1635-1639. doi: 10.4049/jimmunol.170.4.1635

Ariizumi, K., Shen, G. L., Shikano, S., Ritter, R., Zukas, P., Edelbaum, D., et al. (2000a). Cloning of a second dendritic cell-associated C-type lectin (dectin2) and its alternatively spliced isoforms. J. Biol. Chem. 275, 11957-11963. doi: 10.1074/jbc.275.16.11957
Ariizumi, K., Shen, G. L., Shikano, S., Xu, S., Ritter, R., Kumamoto, T., et al. (2000b). Identification of a novel, dendritic cell-associated molecule, dectin1, by subtractive cDNA cloning. J. Biol. Chem. 275, 20157-20167. doi: 10.1074/jbc.M909512199

Bacon, J. S., Jones, D., Farmer, V. C., and Webley, D. M. (1968). The occurrence of alpha(1-3)glucan in Cryptococcus, Schizosaccharomyces and Polyporus species, and its hydrolysis by a Streptomyces culture filtrate lysing cell walls of Cryptococcus. Biochim. Biophys. Acta 158, 313-315. doi: 10.1016/03044165(68)90153-0

Bahia, M. C., Vieira, R. P., Mulloy, B., Hartmann, R., and Bergter, E. B. (1997). The structures of polysaccharides and glycolipids of Aspergillus fumigatus grown in the presence of human serum. Mycopathologia 137, 17-25. doi: 10.1023/A:1006862420963

Bardalaye, P. C., and Nordin, J. H. (1976). Galactosaminogalactan from cell walls of Aspergillus niger. J. Bacteriol. 125, 655-669.

Bardalaye, P. C., and Nordin, J. H. (1977). Chemical structure of the galactomannan from the cell wall of Aspergillus niger. J. Biol. Chem. 252, 2584-2591.

Barreto-Bergter, E., Sassaki, G. L., and De Souza, L. M. (2011). Structural analysis of fungal cerebrosides. Front. Microbiol. 2:239. doi: 10.3389/fmicb.2011.00239

Barreto-Bergter, E., Sassaki, G. L., Wagner, R., Souza, L. M., Souza, M. V., Pinto, M. R., et al. (2008). The opportunistic fungal pathogen Scedosporium prolificans: carbohydrate epitopes of its glycoproteins. Int. J. Biol. Macromol. 42, 93-102. doi: 10.1016/j.ijbiomac.2007.09.015

Barrett, N. A., Maekawa, A., Rahman, O. M., Austen, K. F., and Kanaoka, Y. (2009). Dectin-2 recognition of house dust mite triggers cysteinyl leukotriene generation by dendritic cells. J. Immunol. 182, 1119-1128. doi: 10.4049/jimmunol.182.2.1119

Bates, S., Hughes, H. B., Munro, C. A., Thomas, W. P., MacCallum, D. M., Bertram, G., et al. (2006). Outer chain N-glycans are required for cell wall integrity and virulence of Candida albicans. J. Biol. Chem. 281, 90-98. doi: 10.1074/jbc.M510360200

Bates, S., MacCallum, D. M., Bertram, G., Munro, C. A., Hughes, H. B., Buurman, E. T., et al. (2005). Candida albicans Pmrlp, a secretory pathway P-type $\mathrm{Ca} 2+/ \mathrm{Mn} 2+-\mathrm{ATP} a \mathrm{se}$, is required for glycosylation and virulence. J. Biol. Chem. 280, 23408-23415. doi: 10.1074/jbc.M502162200

Baumann, C. L., Aspalter, I. M., Sharif, O., Pichlmair, A., Blüml, S., Grebien, F., et al. (2010). CD14 is a coreceptor of Toll-like receptors 7 and 9. J. Exp. Med. 207, 2689-2701. doi: 10.1084/jem.20101111

Bernard, M., and Latgé, J. P. (2001). Aspergillus fumigatus cell wall: composition and biosynthesis. Med. Mycol. 39 Suppl. 1, 9-17. doi: 10.1080/mmy.39.1.9.17

Bittencourt, V. C., Figueiredo, R. T., Da Silva, R. B., Mourão -Sá, D. S., Fernandez, P. L., Sassaki, G. L., et al. (2006). An alpha-glucan of Pseudallescheria boydii is involved in fungal phagocytosis and Toll-like receptor activation. J. Biol. Chem. 281, 22614-22623. doi: 10.1074/jbc.M511417200

Bose, N., Chan, A. S., Guerrero, F., Maristany, C. M., Qiu, X., Walsh, R. M., et al. (2013). Binding of soluble yeast $\beta$-glucan to human neutrophils and monocytes is complement-dependent. Front. Immunol. 4:230. doi: 10.3389/fimmu.2013.00230

Bose, N., Wurst, L. R., Chan, A. S., Dudney, C. M., Leroux, M. L., Danielson, M. E., et al. (2014). Differential regulation of oxidative burst by distinct $\beta$ glucan-binding receptors and signaling pathways in human peripheral blood mononuclear cells. Glycobiology 24, 379-391. doi: 10.1093/glycob/cwu005

Brown, G. D., and Gordon, S. (2001). Immune recognition. A new receptor for beta-glucans. Nature 413, 36-37. doi: 10.1038/35092620

Brown, G. D., Herre, J., Williams, D. L., Willment, J. A., Marshall, A. S., and Gordon, S. (2003). Dectin-1 mediates the biological effects of beta-glucans. J. Exp. Med. 197, 1119-1124. doi: 10.1084/jem.20021890

Brown, G. D., Taylor, P. R., Reid, D. M., Willment, J. A., Williams, D. L., Martinez-Pomares, L., et al. (2002). Dectin-1 is a major beta-glucan receptor on macrophages. J. Exp. Med. 196, 407-412. doi: 10.1084/jem.20020470

Brunn, G. J., Bungum, M. K., Johnson, G. B., and Platt, J. L. (2005). Conditional signaling by Toll-like receptor 4. FASEB J. 19, 872-874. doi: 10.1096/fj.04-3211fjet

Bueter, C. L., Lee, C. K., Rathinam, V. A., Healy, G. J., Taron, C. H., Specht, C. A., et al. (2011). Chitosan but not chitin activates the inflammasome by a mechanism dependent upon phagocytosis. J. Biol. Chem. 286, 35447-35455. doi: 10.1074/jbc.M111.274936

Bueter, C. L., Lee, C. K., Wang, J. P., Ostroff, G. R., Specht, C. A., and Levitz, S. M. (2014). Spectrum and mechanisms of inflammasome activation by chitosan. J. Immunol. 192, 5943-5951. doi: 10.4049/jimmunol.1301695 
Bugarcic, A., Hitchens, K., Beckhouse, A. G., Wells, C. A., Ashman, R. B., and Blanchard, H. (2008). Human and mouse macrophage-inducible C-type lectin (Mincle) bind Candida albicans. Glycobiology 18, 679-685. doi: 10.1093/glycob/cwn046

Burgdorf, S., Lukacs-Kornek, V., and Kurts, C. (2006). The mannose receptor mediates uptake of soluble but not of cell-associated antigen for cross-presentation. J. Immunol. 176, 6770-6776. doi: 10.4049/jimmunol.176.11.6770

Cambi, A., Gijzen, K., De Vries, L., Torensma, R., Joosten, B., Adema, G. J., et al. (2003). The C-type lectin DC-SIGN (CD209) is an antigen-uptake receptor for Candida albicans on dendritic cells. Eur. J. Immunol. 33, 532-538. doi: 10.1002/immu.200310029

Cambi, A., Netea, M. G., Mora-Montes, H. M., Gow, N. A., Hato, S. V., Lowman, D. W., et al. (2008). Dendritic cell interaction with Candida albicans critically depends on N-linked mannan. J. Biol. Chem. 283, 20590-20599. doi: 10.1074/jbc.M709334200

Campos, M. A., Almeida, I. C., Takeuchi, O., Akira, S., Valente, E. P., Procópio, D. O., et al. (2001). Activation of Toll-like receptor-2 by glycosylphosphatidylinositol anchors from a protozoan parasite. J. Immunol. 167, 416-423. doi: 10.4049/jimmunol.167.1.416

Costachel, C., Coddeville, B., Latgé, J. P., and Fontaine, T. (2005). Glycosylphosphatidylinositol-anchored fungal polysaccharide in Aspergillus fumigatus. J. Biol. Chem. 280, 39835-39842. doi: 10.1074/jbc.M5101 63200

Da Silva, C. A., Chalouni, C., Williams, A., Hartl, D., Lee, C. G., and Elias, J. A. (2009). Chitin is a size-dependent regulator of macrophage TNF and IL-10 production. J. Immunol. 182, 3573-3582. doi: 10.4049/jimmunol.0802113

Da Silva, C. A., Pochard, P., Lee, C. G., and Elias, J. A. (2010). Chitin particles are multifaceted immune adjuvants. Am. J. Respir. Crit. Care Med. 182, 1482-1491. doi: 10.1164/rccm.200912-1877OC

Davis, T. E., Domer, J. E., and Li, Y. T. (1977). Cell wall studies of Histoplasma capsulatum and Blastomyces dermatitidis using autologous and heterologous enzymes. Infect. Immun. 15, 978-987.

Devillers, A., Courjol, F., Fradin, C., Coste, A., Poulain, D., Pipy, B., et al. (2013). Deficient beta-mannosylation of Candida albicans phospholipomannan affects the proinflammatory response in macrophages. PLoS ONE 8:e84771. doi: 10.1371/journal.pone.0084771

Drickamer, K. (1992). Engineering galactose-binding activity into a C-type mannose-binding protein. Nature 360, 183-186. doi: 10.1038/360183a0

Ezekowitz, R. A., Williams, D. J., Koziel, H., Armstrong, M. Y., Warner, A., Richards, F. F., et al. (1991). Uptake of Pneumocystis carinii mediated by the macrophage mannose receptor. Nature 351, 155-158. doi: 10.1038/351155a0

Figueiredo, R. T., Fernandez, P. L., Dutra, F. F., González, Y., Lopes, L. C., Bittencourt, V. C., et al. (2010). TLR4 recognizes Pseudallescheria boydii conidia and purified rhamnomannans. J. Biol. Chem. 285, 40714-40723. doi: 10.1074/jbc.M110.181255

Figueiredo, R. T., Fernandez, P. L., Mourao-Sa, D. S., Porto, B. N., Dutra, F. F., Alves, L. S., et al. (2007). Characterization of heme as activator of Toll-like receptor 4. J. Biol. Chem. 282, 20221-20229. doi: 10.1074/jbc.M610737200

Fonseca, F. L., Nohara, L. L., Cordero, R. J., Frases, S., Casadevall, A., Almeida, I. C., et al. (2010). Immunomodulatory effects of serotype B glucuronoxylomannan from Cryptococcus gattii correlate with polysaccharide diameter. Infect. Immun. 78, 3861-3870. doi: 10.1128/IAI.00111-10

Fontaine, T., Beauvais, A., Loussert, C., Thevenard, B., Fulgsang, C. C., Ohno, N., et al. (2010). Cell wall alpha1-3glucans induce the aggregation of germinating conidia of Aspergillus fumigatus. Fungal Genet. Biol. 47, 707-712. doi: 10.1016/j.fgb.2010.04.006

Fontaine, T., Delangle, A., Simenel, C., Coddeville, B., Van Vliet, S. J., Van Kooyk, Y., et al. (2011). Galactosaminogalactan, a new immunosuppressive polysaccharide of Aspergillus fumigatus. PLoS Pathog. 7:e1002372. doi: 10.1371/journal.ppat.1002372

Fontaine, T., Simenel, C., Dubreucq, G., Adam, O., Delepierre, M., Lemoine, J., et al. (2000). Molecular organization of the alkali-insoluble fraction of Aspergillus fumigatus cell wall. J. Biol. Chem. 275, 41528. doi: 10.1074/jbc.M909975199

Fradin, C., Poulain, D., and Jouault, T. (2000). beta-1,2-linked oligomannosides from Candida albicans bind to a 32-kilodalton macrophage membrane protein homologous to the mammalian lectin galectin-3. Infect. Immun. 68, 4391-4398. doi: 10.1128/IAI.68.8.4391-4398.2000

Frison, N., Taylor, M. E., Soilleux, E., Bousser, M. T., Mayer, R., Monsigny, M., et al. (2003). Oligolysine-based oligosaccharide clusters: selective recognition and endocytosis by the mannose receptor and dendritic cell-specific intercellular adhesion molecule 3 (ICAM-3)-grabbing nonintegrin. J. Biol. Chem. 278, 23922-23929. doi: 10.1074/jbc.M302483200

Gantner, B. N., Simmons, R. M., Canavera, S. J., Akira, S., and Underhill, D. M. (2003). Collaborative induction of inflammatory responses by dectin-1 and Toll-like receptor 2. J. Exp. Med. 197, 1107-1117. doi: 10.1084/jem.20021787

Gantner, B. N., Simmons, R. M., and Underhill, D. M. (2005). Dectin-1 mediates macrophage recognition of Candida albicans yeast but not filaments. EMBO J. 24, 1277-1286. doi: 10.1038/sj.emboj.7600594

Geijtenbeek, T. B., Torensma, R., Van Vliet, S. J., Van Duijnhoven, G. C., Adema, G. J., Van Kooyk, Y., et al. (2000). Identification of DC-SIGN, a novel dendritic cell-specific ICAM-3 receptor that supports primary immune responses. Cell 100, 575-585. doi: 10.1016/S0092-8674(00)80693-5

Geijtenbeek, T. B., Van Vliet, S. J., Koppel, E. A., Sanchez-Hernandez, M., Vandenbroucke-Grauls, C. M., Appelmelk, B., et al. (2003). Mycobacteria target DC-SIGN to suppress dendritic cell function. J. Exp. Med. 197, 7-17. doi: 10.1084/jem.20021229

Gersuk, G. M., Underhill, D. M., Zhu, L., and Marr, K. A. (2006). Dectin-1 and TLRs permit macrophages to distinguish between different Aspergillus fumigatus cellular states. J. Immunol. 176, 3717-3724. doi: 10.4049/jimmunol.176.6.3717

Goodridge, H. S., Reyes, C. N., Becker, C. A., Katsumoto, T. R., Ma, J., Wolf, A. J., et al. (2011). Activation of the innate immune receptor Dectin-1 upon formation of a 'phagocytic synapse'. Nature 472, 471-475. doi: 10.1038/nature10071

Goodridge, H. S., Shimada, T., Wolf, A. J., Hsu, Y. M., Becker, C. A., Lin, X., et al. (2009a). Differential use of CARD9 by dectin-1 in macrophages and dendritic cells. J. Immunol. 182, 1146-1154. doi: 10.4049/jimmunol.182.2.1146

Goodridge, H. S., Wolf, A. J., and Underhill, D. M. (2009b). Beta-glucan recognition by the innate immune system. Immunol. Rev. 230, 38-50. doi: 10.1111/j.1600-065X.2009.00793.x

Gorin, P. A., and Eveleigh, D. E. (1970). Extracellular 2-acetamido-2-deoxy-Dgalacto-D-galactan from Aspergillus nidulans. Biochemistry 9, 5023-5027. doi: 10.1021/bi00827a029

Gorin, P. A. J., Spencer, J. F. T., and Bhattacharjee, S. S. (1969). Structures of yeast mnnans containing both $\alpha$ - and $\beta$-linked $\mathrm{D}$-mannopyranose units. Can. J. Chem. 47, 1499-1505. doi: 10.1139/v69-248

Gravelat, F. N., Beauvais, A., Liu, H., Lee, M. J., Snarr, B. D., Chen, D., et al. (2013). Aspergillus galactosaminogalactan mediates adherence to host constituents and conceals hyphal $\beta$-glucan from the immune system. PLoS Pathog. 9:e1003575. doi: 10.1371/journal.ppat.1003575

Gresnigt, M. S., Bozza, S., Becker, K. L., Joosten, L. A., Abdollahi-Roodsaz, S., Van Der Berg, W. B., et al. (2014). A polysaccharide virulence factor from Aspergillus fumigatus elicits anti-inflammatory effects through induction of Interleukin-1 receptor antagonist. PLoS Pathog. 10:e1003936. doi: 10.1371/journal.ppat. 1003936

Gringhuis, S. I., Den Dunnen, J., Litjens, M., Van Der Vlist, M., and Geijtenbeek, T. B. (2009). Carbohydrate-specific signaling through the DC-SIGN signalosome tailors immunity to Mycobacterium tuberculosis, HIV-1 and Helicobacter pylori. Nat. Immunol. 10, 1081-1088. doi: 10.1038/ni.1778

Guo, Y., Feinberg, H., Conroy, E., Mitchell, D. A., Alvarez, R., Blixt, O., et al. (2004). Structural basis for distinct ligand-binding and targeting properties of the receptors DC-SIGN and DC-SIGNR. Nat. Struct. Mol. Biol. 11, 591-598. doi: $10.1038 / \mathrm{nsmb} 784$

Haido, R. M., Silva, M. H., Ejzemberg, R., Leitão, E. A., Hearn, V. M., Evans, E. G., et al. (1998). Analysis of peptidogalactomannans from the mycelial surface of Aspergillus fumigatus. Med. Mycol. 36, 313-321. doi: 10.1080/02681219880000491

He, H., Ding, L., Sun, B., Li, F., and Zhan, Q. (2012). Role of galactomannan determinations in bronchoalveolar lavage fluid samples from critically ill patients with chronic obstructive pulmonary disease for the diagnosis of invasive pulmonary aspergillosis: a prospective study. Crit. Care 16, R138. doi: $10.1186 / \mathrm{cc} 11443$

Hidmark, A., Von Saint Paul, A., and Dalpke, A. H. (2012). Cutting edge: TLR13 is a receptor for bacterial RNA. J. Immunol. 189, 2717-2721. doi: 10.4049/jimmunol.1200898

Hobson, R. P., Munro, C. A., Bates, S., MacCallum, D. M., Cutler, J. E., Heinsbroek, S. E., et al. (2004). Loss of cell wall mannosylphosphate in Candida albicans does not influence macrophage recognition. J. Biol. Chem. 279, 39628-39635. doi: 10.1074/jbc.M405003200 
Hohl, T. M., Van Epps, H. L., Rivera, A., Morgan, L. A., Chen, P. L., Feldmesser, M., et al. (2005). Aspergillus fumigatus triggers inflammatory responses by stage-specific beta-glucan display. PLoS Pathog. 1:e30. doi: 10.1371/journal.ppat.0010030

Holers, V. M. (2014). Complement and its receptors: new insights into human disease. Annu. Rev. Immunol. 32, 433-459. doi: 10.1146/annurev-immunol032713-120154

Horisberger, M., Lewis, B. A., and Smith, F. (1972). Structure of a (1 $\rightarrow 3)-\alpha-D-$ glucan (pseudonigeran) of Aspergillus niger NNRL 326 cell wall. Carbohydr. Res. 23, 183-188. doi: 10.1016/S0008-6215(00)88023-4

Hsu, T. L., Cheng, S. C., Yang, W. B., Chin, S. W., Chen, B. H., Huang, M. T., et al. (2009). Profiling carbohydrate-receptor interaction with recombinant innate immunity receptor-Fc fusion proteins. J. Biol. Chem. 284, 34479-34489. doi: 10.1074/jbc.M109.065961

Hynes, R. O. (2002). Integrins: bidirectional, allosteric signaling machines. Cell 110, 673-687. doi: 10.1016/S0092-8674(02)00971-6

Ishikawa, T., Itoh, F., Yoshida, S., Saijo, S., Matsuzawa, T., Gonoi, T., et al. (2013). Identification of distinct ligands for the C-type lectin receptors Mincle and Dectin-2 in the pathogenic fungus Malassezia. Cell Host Microbe 13, 477-488. doi: 10.1016/j.chom.2013.03.008

Jiang, D., Liang, J., Fan, J., Yu, S., Chen, S., Luo, Y., et al. (2005). Regulation of lung injury and repair by Toll-like receptors and hyaluronan. Nat. Med. 11, 1173-1179. doi: 10.1038/nm1315

Jin, M. S., Kim, S. E., Heo, J. Y., Lee, M. E., Kim, H. M., Paik, S. G., et al. (2007). Crystal structure of the TLR1-TLR2 heterodimer induced by binding of a triacylated lipopeptide. Cell 130, 1071-1082. doi: 10.1016/j.cell.2007.09.008

Johnson, G. B., Brunn, G. J., Kodaira, Y., and Platt, J. L. (2002). Receptor-mediated monitoring of tissue well-being via detection of soluble heparan sulfate by Tolllike receptor 4. J. Immunol. 168, 5233-5239. doi: 10.4049/jimmunol.168.10.5233

Jouault, T., Ibata-Ombetta, S., Takeuchi, O., Trinel, P. A., Sacchetti, P., Lefebvre, P., et al. (2003). Candida albicans phospholipomannan is sensed through toll-like receptors. J. Infect. Dis. 188, 165-172. doi: 10.1086/375784

Kakutani, R., Adachi, Y., Takata, H., Kuriki, T., and Ohno, N. (2012). Essential role of Toll-like receptor 2 in macrophage activation by glycogen. Glycobiology 22, 146-159. doi: 10.1093/glycob/cwr122

Kanetsuna, F., and Carbonell, L. M. (1970). Cell wall glucans of the yeast and mycelial forms of Paracoccidioides brasiliensis. J. Bacteriol. 101, 675-680.

Kanetsuna, F., and Carbonell, L. M. (1971). Cell wall composition of the yeastlike and mycelial forms of Blastomyces dermatitidis. J. Bacteriol. 106, 946-948.

Kanetsuna, F., Carbonell, L. M., Azuma, I., and Yamamura, Y. (1972). Biochemical studies on the thermal dimorphism of Paracoccidioides brasiliensis. J. Bacteriol. $110,208-218$.

Kanetsuna, F., Carbonell, L. M., Gil, F., and Azuma, I. (1974). Chemical and ultrastructural studies on the cell walls of the yeastlike and mycelial forms of Histoplasma capsulatum. Mycopathol. Mycol. Appl. 54, 1-13. doi: 10.1007/BF02055967

Kang, J. Y., Nan, X., Jin, M. S., Youn, S. J., Ryu, Y. H., Mah, S., et al. (2009). Recognition of lipopeptide patterns by Toll-like receptor 2-Toll-like receptor 6 heterodimer. Immunity 31, 873-884. doi: 10.1016/j.immuni.2009.09.018

Kang, P. B., Azad, A. K., Torrelles, J. B., Kaufman, T. M., Beharka, A., Tibesar, E., et al. (2005). The human macrophage mannose receptor directs Mycobacterium tuberculosis lipoarabinomannan-mediated phagosome biogenesis. J. Exp. Med. 202, 987-999. doi: 10.1084/jem.20051239

Kelley, S. L., Lukk, T., Nair, S. K., and Tapping, R. I. (2013). The crystal structure of human soluble CD14 reveals a bent solenoid with a hydrophobic aminoterminal pocket. J. Immunol. 190, 1304-1311. doi: 10.4049/jimmunol.1202446

Kennedy, A. D., Willment, J. A., Dorward, D. W., Williams, D. L., Brown, G. D., and Deleo, F. R. (2007). Dectin-1 promotes fungicidal activity of human neutrophils. Eur. J. Immunol. 37, 467-478. doi: 10.1002/eji.200636653

Kim, J. I., Lee, C. J., Jin, M. S., Lee, C. H., Paik, S. G., Lee, H., et al. (2005). Crystal structure of CD14 and its implications for lipopolysaccharide signaling. J. Biol. Chem. 280, 11347-11351. doi: 10.1074/jbc.M414607200

Kitchens, R. L., and Munford, R. S. (1995). Enzymatically deacylated lipopolysaccharide (LPS) can antagonize LPS at multiple sites in the LPS recognition pathway. J. Biol. Chem. 270, 9904-9910. doi: 10.1074/jbc.270.17.9904

Kobayashi, H., Shibata, N., and Suzuki, S. (1992). Evidence for oligomannosyl residues containing both beta-1,2 and alpha-1,2 linkages as a serotype A-specific epitope(s) in mannans of Candida albicans. Infect. Immun. 60, 2106-2109.
Kolatkar, A. R., Leung, A. K., Isecke, R., Brossmer, R., Drickamer, K., and Weis, W. I. (1998). Mechanism of $\mathrm{N}$-acetylgalactosamine binding to a C-type animal lectin carbohydrate-recognition domain. J. Biol. Chem. 273, 19502-19508. doi: 10.1074/jbc.273.31.19502

Kolatkar, A. R., and Weis, W. I. (1996). Structural basis of galactose recognition by C-type animal lectins. J. Biol. Chem. 271, 6679-6685. doi: 10.1074/jbc.271.12.6679

Krishnegowda, G., Hajjar, A. M., Zhu, J., Douglass, E. J., Uematsu, S., Akira, S., et al. (2005). Induction of proinflammatory responses in macrophages by the glycosylphosphatidylinositols of Plasmodium falciparum: cell signaling receptors, glycosylphosphatidylinositol (GPI) structural requirement, and regulation of GPI activity. J. Biol. Chem. 280, 8606-8616. doi: 10.1074/jbc.M413541200

Kwon, D. S., Gregorio, G., Bitton, N., Hendrickson, W. A., and Littman, D. R. (2002). DC-SIGN-mediated internalization of HIV is required for transenhancement of T cell infection. Immunity 16, 135-144. doi: 10.1016/S10747613(02)00259-5

Lam, J. S., Huang, H., and Levitz, S. M. (2007). Effect of differential N-linked and O-linked mannosylation on recognition of fungal antigens by dendritic cells. PLoS ONE 2:e1009. doi: 10.1371/journal.pone.0001009

Latgé, J. P. (2010). Tasting the fungal cell wall. Cell. Microbiol. 12, 863-872. doi: 10.1111/j.1462-5822.2010.01474.x

Latgé, J. P., Kobayashi, H., Debeaupuis, J. P., Diaquin, M., Sarfati, J., Wieruszeski, J. M., et al. (1994). Chemical and immunological characterization of the extracellular galactomannan of Aspergillus fumigatus. Infect. Immun. 62, 5424-5433.

Le Cabec, V., Emorine, L. J., Toesca, I., Cougoule, C., and Maridonneau-Parini, I. (2005). The human macrophage mannose receptor is not a professional phagocytic receptor. J. Leukoc. Biol. 77, 934-943. doi: 10.1189/jlb.1204705

Lee, H. K., Dunzendorfer, S., Soldau, K., and Tobias, P. S. (2006). Double-stranded RNA-mediated TLR3 activation is enhanced by CD14. Immunity 24, 153-163. doi: 10.1016/j.immuni.2005.12.012

Lee, R. T., Hsu, T. L., Huang, S. K., Hsieh, S. L., Wong, C. H., and Lee, Y. C. (2011) Survey of immune-related, mannose/fucose-binding C-type lectin receptors reveals widely divergent sugar-binding specificities. Glycobiology 21, 512-520. doi: $10.1093 /$ glycob/cwq193

Leibundgut-Landmann, S., Osorio, F., Brown, G. D., and Reis E Sousa, C. (2008). Stimulation of dendritic cells via the dectin-1/Syk pathway allows priming of cytotoxic T-cell responses. Blood 112, 4971-4980. doi: 10.1182/blood-2008-05158469

Leitao, E. A., Bittencourt, V. C., Haido, R. M., Valente, A. P., Peter-Katalinic, J., Letzel, M., et al. (2003). Beta-galactofuranose-containing O-linked oligosaccharides present in the cell wall peptidogalactomannan of Aspergillus fumigatus contain immunodominant epitopes. Glycobiology 13, 681-692. doi: 10.1093/glycob/cwg089

Lemaitre, B., Nicolas, E., Michaut, L., Reichhart, J. M., and Hoffmann, J. A. (1996). The dorsoventral regulatory gene cassette spätzle/Toll/cactus controls the potent antifungal response in Drosophila adults. Cell 86, 973-983. doi: 10.1016/S00928674(00)80172-5

Leteux, C., Chai, W., Loveless, R. W., Yuen, C. T., Uhlin-Hansen, L., Combarnous, Y., et al. (2000). The cysteine-rich domain of the macrophage mannose receptor is a multispecific lectin that recognizes chondroitin sulfates $\mathrm{A}$ and $\mathrm{B}$ and sulfated oligosaccharides of blood group Lewis(a) and Lewis(x) types in addition to the sulfated N-glycans of lutropin. J. Exp. Med. 191, 1117-1126. doi: 10.1084/jem.191.7.1117

Li, X. D., and Chen, Z. J. (2012). Sequence specific detection of bacterial $23 \mathrm{~S}$ ribosomal RNA by TLR13. Elife 1:e00102. doi: 10.7554/eLife.00102

Li, X., Utomo, A., Cullere, X., Choi, M. M., Milner, D. A., Venkatesh, D., et al. (2011). The $\beta$-glucan receptor Dectin-1 activates the integrin Mac-1 in neutrophils via Vav protein signaling to promote Candida albicans clearance. Cell Host Microbe 10, 603-615. doi: 10.1016/j.chom.2011.10.009

Liu, Y., Chirino, A. J., Misulovin, Z., Leteux, C., Feizi, T., Nussenzweig, M. C., et al. (2000). Crystal structure of the cysteine-rich domain of mannose receptor complexed with a sulfated carbohydrate ligand. J. Exp. Med. 191, 1105-1116. doi: 10.1084/jem.191.7.1105

Lopes, L. C., Da Silva, M. I., Bittencourt, V. C., Figueiredo, R. T., Rollin-Pinheiro, R., Sassaki, G. L., et al. (2011). Glycoconjugates and polysaccharides from the Scedosporium/Pseudallescheria boydii complex: structural characterisation, involvement in cell differentiation, cell recognition and virulence. Mycoses 54 Suppl. 3, 28-36. doi: 10.1111/j.1439-0507.2011.02105.x 
Lopes-Bezerra, L. M. (2011). Sporothrix schenckii cell wall peptidorhamnomannans. Front. Microbiol. 2:243. doi: 10.3389/fmicb.2011.00243

Loussert, C., Schmitt, C., Prevost, M. C., Balloy, V., Fadel, E., Philippe, B., et al. (2010). In vivo biofilm composition of Aspergillus fumigatus. Cell. Microbiol. 12, 405-410. doi: 10.1111/j.1462-5822.2009.01409.x

Lowman, D. W., Greene, R. R., Bearden, D. W., Kruppa, M. D., Pottier, M., Monteiro, M. A., et al. (2014). Novel structural features in Candida albicans hyphal glucan provide a basis for differential innate immune recognition of hyphae versus yeast. J. Biol. Chem. 289, 3432-3443. doi: 10.1074/jbc.M113.529131

Mambula, S. S., Sau, K., Henneke, P., Golenbock, D. T., and Levitz, S. M. (2002). Toll-like receptor (TLR) signaling in response to Aspergillus fumigatus. J. Biol. Chem. 277, 39320-39326. doi: 10.1074/jbc.M201683200

Martinez-Pomares, L. (2012). The mannose receptor. J. Leukoc. Biol. 92, 1177-1186. doi: $10.1189 /$ jlb.0512231

Masuoka, J. (2004). Surface glycans of Candida albicans and other pathogenic fungi: physiological roles, clinical uses, and experimental challenges. Clin. Microbiol. Rev. 17, 281-310. doi: 10.1128/CMR.17.2.281-310.2004

Matsumoto, M., Tanaka, T., Kaisho, T., Sanjo, H., Copeland, N. G., Gilbert, D. J., et al. (1999). A novel LPS-inducible C-type lectin is a transcriptional target of NF-IL6 in macrophages. J. Immunol. 163, 5039-5048.

McGreal, E. P., Rosas, M., Brown, G. D., Zamze, S., Wong, S. Y., Gordon, S., et al. (2006). The carbohydrate-recognition domain of Dectin-2 is a C-type lectin with specificity for high mannose. Glycobiology 16, 422-430. doi: 10.1093/gly$\mathrm{cob} / \mathrm{cwj077}$

Mitchell, D. A., Fadden, A. J., and Drickamer, K. (2001). A novel mechanism of carbohydrate recognition by the C-type lectins DC-SIGN and DC-SIGNR. Subunit organization and binding to multivalent ligands. J. Biol. Chem. 276, 28939-28945. doi: 10.1074/jbc.M104565200

Mora-Montes, H. M., Netea, M. G., Ferwerda, G., Lenardon, M. D., Brown, G. D., Mistry, A. R., et al. (2011). Recognition and blocking of innate immunity cells by Candida albicans chitin. Infect. Immun. 79, 1961-1970. doi: 10.1128/IAI. 01282-10

Munro, C. A., Bates, S., Buurman, E. T., Hughes, H. B., MacCallum, D. M., Bertram, G., et al. (2005). Mntlp and Mnt2p of Candida albicans are partially redundant alpha-1,2-mannosyltransferases that participate in O-linked mannosylation and are required for adhesion and virulence. J. Biol. Chem. 280, 1051-1060. doi: 10.1074/jbc.M411413200

Munro, C. A., and Gow, N. A. (2001). Chitin synthesis in human pathogenic fungi. Med. Mycol. 39 Suppl. 1, 41-53. doi: 10.1080/744118878

Netea, M. G., Gow, N. A., Munro, C. A., Bates, S., Collins, C., Ferwerda, G., et al. (2006). Immune sensing of Candida albicans requires cooperative recognition of mannans and glucans by lectin and Toll-like receptors. J. Clin. Invest. 116, 1642-1650. doi: 10.1172/JCI27114

Nishiyama, A., Tsuji, S., Yamashita, M., Henriksen, R. A., Myrvik, Q. N., and Shibata, Y. (2006). Phagocytosis of N-acetyl-D-glucosamine particles, a Th1 adjuvant, by RAW 264.7 cells results in MAPK activation and TNF-alpha, but not IL-10, production. Cell. Immunol. 239, 103-112. doi: 10.1016/j.cellimm.2006.04.003

Oldenburg, M., Krüger, A., Ferstl, R., Kaufmann, A., Nees, G., Sigmund, A., et al. (2012). TLR13 recognizes bacterial 23S rRNA devoid of erythromycin resistance-forming modification. Science 337, 1111-1115. doi: 10.1126/science. 1220363

Park, B. S., Song, D. H., Kim, H. M., Choi, B. S., Lee, H., and Lee, J. O. (2009). The structural basis of lipopolysaccharide recognition by the TLR4-MD-2 complex. Nature 458, 1191-1195. doi: 10.1038/nature07830

Pinto, M. R., De Sá, A. C., Limongi, C. L., Rozental, S., Santos, A. L., and BarretoBergter, E. (2004). Involvement of peptidorhamnomannan in the interaction of Pseudallescheria boydii and HEp2 cells. Microbes Infect. 6, 1259-1267. doi: 10.1016/j.micinf.2004.07.006

Pinto, M. R., Gorin, P. A., Wait, R., Mulloy, B., and Barreto-Bergter, E. (2005). Structures of the O-linked oligosaccharides of a complex glycoconjugate from Pseudallescheria boydii. Glycobiology 15, 895-904. doi: 10.1093/glycob/ cwi084

Pinto, M. R., Mulloy, B., Haido, R. M., Travassos, L. R., and Barreto Bergter, E. (2001). A peptidorhamnomannan from the mycelium of Pseudallescheria boydii is a potential diagnostic antigen of this emerging human pathogen. Microbiology 147, 1499-1506.
Poltorak, A., He, X., Smirnova, I., Liu, M. Y., Van Huffel, C., Du, X., et al. (1998). Defective LPS signaling in C3H/HeJ and C57BL/10ScCr mice: mutations in Tlr4 gene. Science 282, 2085-2088. doi: 10.1126/science.282.5396.2085

Previato, J. O., Gorin, P. A. J., Haskins, R. H., and Travassos, L. R. (1979). Soluble and insoluble glucans from different cell types of the human pathogen Sporothrix schenckii. Exp. Mycol. 3, 92-105. doi: 10.1016/S0147-5975(79) 80021-3

Qi, C., Cai, Y., Gunn, L., Ding, C., Li, B., Kloecker, G., et al. (2011). Differential pathways regulating innate and adaptive antitumor immune responses by particulate and soluble yeast-derived $\beta$-glucans. Blood 117, 6825-6836. doi: 10.1182/blood-2011-02-339812

Rajaram, M. V., Brooks, M. N., Morris, J. D., Torrelles, J. B., Azad, A. K., and Schlesinger, L. S. (2010). Mycobacterium tuberculosis activates human macrophage peroxisome proliferator-activated receptor gamma linking mannose receptor recognition to regulation of immune responses. J. Immunol. 185, 929-942. doi: 10.4049/jimmunol.1000866

Rappleye, C. A., Eissenberg, L. G., and Goldman, W. E. (2007). Histoplasma capsulatum alpha-(1,3)-glucan blocks innate immune recognition by the beta-glucan receptor. Proc. Natl. Acad. Sci. U.S.A. 104, 1366-1370. doi: 10.1073/pnas.0609848104

Reese, T. A., Liang, H. E., Tager, A. M., Luster, A. D., Van Rooijen, N., Voehringer, D., et al. (2007). Chitin induces accumulation in tissue of innate immune cells associated with allergy. Nature 447, 92-96. doi: 10.1038/nature05746

Robinson, M. J., Osorio, F., Rosas, M., Freitas, R. P., Schweighoffer, E., Gross, O., et al. (2009). Dectin-2 is a Syk-coupled pattern recognition receptor crucial for Th17 responses to fungal infection. J. Exp. Med. 206, 2037-2051. doi: 10.1084/jem.20082818

Rogers, N. C., Slack, E. C., Edwards, A. D., Nolte, M. A., Schulz, O., Schweighoffer, E., et al. (2005). Syk-dependent cytokine induction by Dectin-1 reveals a novel pattern recognition pathway for $\mathrm{C}$ type lectins. Immunity 22, 507-517. doi: 10.1016/j.immuni.2005.03.004

Rosas, M., Liddiard, K., Kimberg, M., Faro-Trindade, I., McDonald, J. U., Williams, D. L., et al. (2008). The induction of inflammation by dectin-1 in vivo is dependent on myeloid cell programming and the progression of phagocytosis. J. Immunol. 181, 3549-3557. doi: 10.4049/jimmunol.181.5.3549

Ross, G. D. (2000). Regulation of the adhesion versus cytotoxic functions of the Mac-1/CR3/alphaMbeta2-integrin glycoprotein. Crit. Rev. Immunol. 20, 197-222. doi: 10.1615/CritRevImmunol.v20.i3.20

Ruiz-Herrera, J., Elorza, M. V., Valentín, E., and Sentandreu, R. (2006). Molecular organization of the cell wall of Candida albicans and its relation to pathogenicity. FEMS Yeast Res. 6, 14-29. doi: 10.1111/j.1567-1364.2005.00017.x

Saijo, S., Ikeda, S., Yamabe, K., Kakuta, S., Ishigame, H., Akitsu, A., et al. (2010). Dectin-2 recognition of alpha-mannans and induction of Th17 cell differentiation is essential for host defense against Candida albicans. Immunity 32, 681-691. doi: 10.1016/j.immuni.2010.05.001

Sancho, D., and Reis E Sousa, C. (2012). Signaling by myeloid C-type lectin receptors in immunity and homeostasis. Annu. Rev. Immunol. 30, 491-529. doi: 10.1146/annurev-immunol-031210-101352

Sandor, F., Latz, E., Re, F., Mandell, L., Repik, G., Golenbock, D. T., et al. (2003). Importance of extra- and intracellular domains of TLR1 and TLR2 in NFkappa B signaling. J. Cell Biol. 162, 1099-1110. doi: 10.1083/jcb.200304093

Sato, K., Yang, X. L., Yudate, T., Chung, J. S., Wu, J., Luby-Phelps, K., et al. (2006). Dectin-2 is a pattern recognition receptor for fungi that couples with the $\mathrm{Fc}$ receptor gamma chain to induce innate immune responses. J. Biol. Chem. 281, 38854-38866. doi: 10.1074/jbc.M606542200

Schaefer, L., Babelova, A., Kiss, E., Hausser, H. J., Baliova, M., Krzyzankova, M., et al. (2005). The matrix component biglycan is proinflammatory and signals through Toll-like receptors 4 and 2 in macrophages. J. Clin. Invest. 115, 2223-2233. doi: 10.1172/JCI23755

Scheibner, K. A., Lutz, M. A., Boodoo, S., Fenton, M. J., Powell, J. D., and Horton, M. R. (2006). Hyaluronan fragments act as an endogenous danger signal by engaging TLR2. J. Immunol. 177, 1272-1281. doi: 10.4049/jimmunol.177.2.1272

Schröder, N. W., Heine, H., Alexander, C., Manukyan, M., Eckert, J., Hamann, L., et al. (2004). Lipopolysaccharide binding protein binds to triacylated and diacylated lipopeptides and mediates innate immune responses. J. Immunol. 173, 2683-2691. doi: 10.4049/jimmunol.173.4.2683

Schromm, A. B., Lien, E., Henneke, P., Chow, J. C., Yoshimura, A., Heine, H., et al. (2001). Molecular genetic analysis of an endotoxin nonresponder mutant cell 
line: a point mutation in a conserved region of MD-2 abolishes endotoxininduced signaling. J. Exp. Med. 194, 79-88. doi: 10.1084/jem.194.1.79

Schwandner, R., Dziarski, R., Wesche, H., Rothe, M., and Kirschning, C. J. (1999). Peptidoglycan- and lipoteichoic acid-induced cell activation is mediated by tolllike receptor 2. J. Biol. Chem. 274, 17406-17409. doi: 10.1074/jbc.274.25.17406

Serrano-Gómez, D., Domínguez-Soto, A., Ancochea, J., Jimenez-Heffernan, J. A., Leal, J. A., and Corbí, A. L. (2004). Dendritic cell-specific intercellular adhesion molecule 3-grabbing nonintegrin mediates binding and internalization of Aspergillus fumigatus conidia by dendritic cells and macrophages. J. Immunol. 173, 5635-5643. doi: 10.4049/jimmunol.173.9.5635

Shibata, N., Kobayashi, H., Okawa, Y., and Suzuki, S. (2003). Existence of novel beta-1,2 linkage-containing side chain in the mannan of Candida lusitaniae, antigenically related to Candida albicans serotype A. Eur. J. Biochem. 270, 2565-2575. doi: 10.1046/j.1432-1033.2003.03622.x

Shimazu, R., Akashi, S., Ogata, H., Nagai, Y., Fukudome, K., Miyake, K., et al. (1999). MD-2, a molecule that confers lipopolysaccharide responsiveness on Toll-like receptor 4. J. Exp. Med. 189, 1777-1782. doi: 10.1084/jem.189.11.1777

Shoham, S., Huang, C., Chen, J. M., Golenbock, D. T., and Levitz, S. M. (2001). Toll-like receptor 4 mediates intracellular signaling without TNF-alpha release in response to Cryptococcus neoformans polysaccharide capsule. J. Immunol. 166, 4620-4626. doi: 10.4049/jimmunol.166.7.4620

Steele, C., Rapaka, R. R., Metz, A., Pop, S. M., Williams, D. L., Gordon, S., et al. (2005). The beta-glucan receptor dectin-1 recognizes specific morphologies of Aspergillus fumigatus. PLoS Pathog. 1:e42. doi: 10.1371/journal.ppat.0010042

Stewart, T. S., and Ballou, C. E. (1968). A comparison of yeast mannans and phosphomannans by acetolysis. Biochemistry 7, 1855-1863. doi: 10.1021/bi00845a033

Tachado, S. D., Zhang, J., Zhu, J., Patel, N., Cushion, M., and Koziel, H. (2007). Pneumocystis-mediated IL- 8 release by macrophages requires coexpression of mannose receptors and TLR2. J. Leukoc. Biol. 81, 205-211. doi: 10.1189/jlb.1005580

Tada, H., Nemoto, E., Shimauchi, H., Watanabe, T., Mikami, T., Matsumoto, T., et al. (2002). Saccharomyces cerevisiae- and Candida albicans-derived mannan induced production of tumor necrosis factor alpha by human monocytes in a CD14- and Toll-like receptor 4-dependent manner. Microbiol. Immunol. 46, 503-512. doi: 10.1111/j.1348-0421.2002.tb02727.x

Tailleux, L., Schwartz, O., Herrmann, J. L., Pivert, E., Jackson, M., Amara, A., et al. (2003). DC-SIGN is the major Mycobacterium tuberculosis receptor on human dendritic cells. J. Exp. Med. 197, 121-127. doi: 10.1084/jem.20021468

Takeuchi, O., and Akira, S. (2010). Pattern recognition receptors and inflammation. Cell 140, 805-820. doi: 10.1016/j.cell.2010.01.022

Takeuchi, O., Kaufmann, A., Grote, K., Kawai, T., Hoshino, K., Morr, M., et al. (2000). Cutting edge: preferentially the R-stereoisomer of the mycoplasmal lipopeptide macrophage-activating lipopeptide- 2 activates immune cells through a toll-like receptor 2- and MyD88-dependent signaling pathway. J. Immunol. 164, 554-557. doi: 10.4049/jimmunol.164.2.554

Takeuchi, O., Kawai, T., Mühlradt, P. F., Morr, M., Radolf, J. D., Zychlinsky, A., et al. (2001). Discrimination of bacterial lipoproteins by Toll-like receptor 6 . Int. Immunol. 13, 933-940. doi: 10.1093/intimm/13.7.933

Takeuchi, O., Sato, S., Horiuchi, T., Hoshino, K., Takeda, K., Dong, Z., et al. (2002). Cutting edge: role of Toll-like receptor 1 in mediating immune response to microbial lipoproteins. J. Immunol. 169, 10-14. doi: 10.4049/jimmunol.169.1.10

Tapping, R. I., and Tobias, P. S. (2003). Mycobacterial lipoarabinomannan mediates physical interactions between TLR1 and TLR2 to induce signaling. J. Endotoxin Res. 9, 264-268. doi: 10.1179/096805103225001477

Tassaneetrithep, B., Burgess, T. H., Granelli-Piperno, A., Trumpfheller, C., Finke, J., Sun, W., et al. (2003). DC-SIGN (CD209) mediates dengue virus infection of human dendritic cells. J. Exp. Med. 197, 823-829. doi: 10.1084/jem. 20021840

Taylor, M. E., Bezouska, K., and Drickamer, K. (1992). Contribution to ligand binding by multiple carbohydrate-recognition domains in the macrophage mannose receptor. J. Biol. Chem. 267, 1719-1726.

Taylor, M. E., and Drickamer, K. (1993). Structural requirements for high affinity binding of complex ligands by the macrophage mannose receptor. J. Biol. Chem. 268, 399-404.

Taylor, P. R., Brown, G. D., Reid, D. M., Willment, J. A., Martinez-Pomares, L., Gordon, S., et al. (2002). The beta-glucan receptor, dectin-1, is predominantly expressed on the surface of cells of the monocyte/macrophage and neutrophil lineages. J. Immunol. 169, 3876-3882. doi: 10.4049/jimmunol.169.7.3876
Taylor, P. R., Reid, D. M., Heinsbroek, S. E., Brown, G. D., Gordon, S., and Wong, S. Y. (2005). Dectin-2 is predominantly myeloid restricted and exhibits unique activation-dependent expression on maturing inflammatory monocytes elicited in vivo. Eur. J. Immunol. 35, 2163-2174. doi: 10.1002/eji.200425785

Taylor, P. R., Roy, S., Leal, S. M., Sun, Y., Howell, S. J., Cobb, B. A., et al. (2014). Activation of neutrophils by autocrine IL-17A-IL-17RC interactions during fungal infection is regulated by IL-6, IL-23, ROR $\gamma \mathrm{t}$ and dectin-2. Nat. Immunol. 15, 143-151. doi: 10.1038/ni.2797

Teering, S., Verreth, A., Peeters, A., Van Regenmortel, N., De Laet, I., Schoonheydt, K., et al. (2014). Prognostic value of serum galactomannan in mixed ICU patients: a retrospective observational study. Anaesthesiol. Intensive Ther. 46, 145-154. doi: 10.5603/AIT.2014.0027

Termeer, C., Benedix, F., Sleeman, J., Fieber, C., Voith, U., Ahrens, T., et al. (2002). Oligosaccharides of Hyaluronan activate dendritic cells via toll-like receptor 4 . J. Exp. Med. 195, 99-111. doi: 10.1084/jem.20001858

Thornton, B. P., Vetvicka, V., Pitman, M., Goldman, R. C., and Ross, G. D. (1996). Analysis of the sugar specificity and molecular location of the beta-glucanbinding lectin site of complement receptor type 3 (CD11b/CD18). J. Immunol. 156, 1235-1246.

Tischer, C. A., Gorin, P. A. J., De Sousa, M. B., and Barreto-Bergter, E. (2002). Structures of phosphonogalactomannans isolated from mycelia of Aspergillus versicolor. Carbohydr. Polym. 49, 225-230. doi: 10.1016/S0144-8617(01)00325-3

Torrelles, J. B., Azad, A. K., and Schlesinger, L. S. (2006). Fine discrimination in the recognition of individual species of phosphatidyl-myo-inositol mannosides from Mycobacterium tuberculosis by C-type lectin pattern recognition receptors. J. Immunol. 177, 1805-1816. doi: 10.4049/jimmunol.177.3.1805

Trinel, P. A., Delplace, F., Maes, E., Zanetta, J. P., Mille, C., Coddeville, B., et al. (2005). Candida albicans serotype B strains synthesize a serotype-specific phospholipomannan overexpressing a beta-1,2-linked mannotriose. Mol. Microbiol. 58, 984-998. doi: 10.1111/j.1365-2958.2005.04890.x

Trinel, P. A., Maes, E., Zanetta, J. P., Delplace, F., Coddeville, B., Jouault, T., et al. (2002). Candida albicans phospholipomannan, a new member of the fungal mannose inositol phosphoceramide family. J. Biol. Chem. 277, 37260-37271. doi: 10.1074/jbc.M202295200

Van Bruggen, R., Drewniak, A., Jansen, M., Van Houdt, M., Roos, D., Chapel, H., et al. (2009). Complement receptor 3, not Dectin-1, is the major receptor on human neutrophils for beta-glucan-bearing particles. Mol. Immunol. 47, 575-581. doi: 10.1016/j.molimm.2009.09.018

Van De Veerdonk, F. L., Marijnissen, R. J., Kullberg, B. J., Koenen, H. J., Cheng, S. C., Joosten, I., et al. (2009). The macrophage mannose receptor induces IL-17 in response to Candida albicans. Cell Host Microbe 5, 329-340. doi: 10.1016/j.chom.2009.02.006

Van Dyken, S. J., Garcia, D., Porter, P., Huang, X., Quinlan, P. J., Blanc, P. D., et al. (2011). Fungal chitin from asthma-associated home environments induces eosinophilic lung infiltration. J. Immunol. 187, 2261-2267. doi: 10.4049/jimmunol.1100972

Van Kooyk, Y., and Geijtenbeek, T. B. (2003). DC-SIGN: escape mechanism for pathogens. Nat. Rev. Immunol. 3, 697-709. doi: 10.1038/nri1182

Van Liempt, E., Imberty, A., Bank, C. M., Van Vliet, S. J., Van Kooyk, Y., Geijtenbeek, T. B., et al. (2004). Molecular basis of the differences in binding properties of the highly related C-type lectins DC-SIGN and L-SIGN to Lewis X trisaccharide and Schistosoma mansoni egg antigens. J. Biol. Chem. 279, 33161-33167. doi: 10.1074/jbc.M404988200

Villeneuve, C., Gilleron, M., Maridonneau-Parini, I., Daffé, M., Astarie-Dequeker, C., and Etienne, G. (2005). Mycobacteria use their surface-exposed glycolipids to infect human macrophages through a receptor-dependent process. J. Lipid Res. 46, 475-483. doi: 10.1194/jlr.M400308-JLR200

Wagener, J., Malireddi, R. K., Lenardon, M. D., Köberle, M., Vautier, S., MacCallum, D. M., et al. (2014). Fungal chitin dampens inflammation through IL-10 induction mediated by NOD2 and TLR9 activation. PLoS Pathog. 10:e1004050. doi: 10.1371/journal.ppat.1004050

Wang, J. E., Warris, A., Ellingsen, E. A., Jørgensen, P. F., Flo, T. H., Espevik, T., et al. (2001). Involvement of CD14 and toll-like receptors in activation of human monocytes by Aspergillus fumigatus hyphae. Infect. Immun. 69, 2402-2406. doi: 10.1128/IAI.69.4.2402-2406.2001

Weck, M. M., Appel, S., Werth, D., Sinzger, C., Bringmann, A., Grünebach, F., et al. (2008). hDectin-1 is involved in uptake and cross-presentation of cellular antigens. Blood 111, 4264-4272. doi: 10.1182/blood-2006-10-051375 
Wells, C. A., Salvage-Jones, J. A., Li, X., Hitchens, K., Butcher, S., Murray, R. Z., et al. (2008). The macrophage-inducible C-type lectin, mincle, is an essential component of the innate immune response to Candida albicans. J. Immunol. 180, 7404-7413. doi: 10.4049/jimmunol.180.11.7404

Willment, J. A., Marshall, A. S., Reid, D. M., Williams, D. L., Wong, S. Y., Gordon, S., et al. (2005). The human beta-glucan receptor is widely expressed and functionally equivalent to murine Dectin-1 on primary cells. Eur. J. Immunol. 35, 1539-1547. doi: 10.1002/eji.200425725

Xie, X., and Lipke, P. N. (2010). On the evolution of fungal and yeast cell walls. Yeast 27, 479-488. doi: 10.1002/yea.1787

Yamasaki, S., Ishikawa, E., Sakuma, M., Hara, H., Ogata, K., and Saito, T. (2008). Mincle is an ITAM-coupled activating receptor that senses damaged cells. Nat. Immunol. 9, 1179-1188. doi: 10.1038/ni.1651

Yamasaki, S., Matsumoto, M., Takeuchi, O., Matsuzawa, T., Ishikawa, E., Sakuma, M., et al. (2009). C-type lectin Mincle is an activating receptor for pathogenic fungus, Malassezia. Proc. Natl. Acad. Sci. U.S.A. 106, 1897-1902. doi: 10.1073/pnas.0805177106

Yoshitomi, H., Sakaguchi, N., Kobayashi, K., Brown, G. D., Tagami, T., Sakihama, T., et al. (2005). A role for fungal \{beta\}-glucans and their receptor Dectin-1 in the induction of autoimmune arthritis in genetically susceptible mice. J. Exp. Med. 201, 949-960. doi: 10.1084/jem.20041758

Yu, R. J., Bishop, C. T., Cooper, F. P., Hasenclever, H. F., and Blank, F. (1967). Structural studies of mannans from Candida albicans (serotypes A and B), Candida parapsilosis, Candida stellatoidea, and Candida tropicalis. Can. J. Chem. 45, 2205-2211. doi: 10.1139/v67-356

Zanoni, I., and Granucci, F. (2013). Role of CD14 in host protection against infections and in metabolism regulation. Front. Cell. Infect. Microbiol. 3:32. doi: $10.3389 /$ fcimb. 2013.00032
Zelensky, A. N., and Gready, J. E. (2005). The C-type lectin-like domain superfamily. FEBS J. 272, 6179-6217. doi: 10.1111/j.1742-4658.2005.05031.x

Zhu, L. L., Zhao, X. Q., Jiang, C., You, Y., Chen, X. P., Jiang, Y. Y., et al. (2013). C-type lectin receptors Dectin-3 and Dectin-2 form a heterodimeric patternrecognition receptor for host defense against fungal infection. Immunity 39, 324-334. doi: 10.1016/j.immuni.2013.05.017

Zonneveld, B. J. (1972). Morphogenesis in Aspergillus nidulans. The significance of a alpha-1, 3-glucan of the cell wall and alpha-1,3-glucanase for cleistothecium development. Biochim. Biophys. Acta 273, 174-187. doi: 10.1016/03044165(72)90205-X

Conflict of Interest Statement: The authors declare that the research was conducted in the absence of any commercial or financial relationships that could be construed as a potential conflict of interest.

Received: 07 July 2014; accepted: 25 September 2014; published online: 14 October 2014.

Citation: Barreto-Bergter E and Figueiredo RT (2014) Fungal glycans and the innate immune recognition. Front. Cell. Infect. Microbiol. 4:145. doi: 10.3389/fcimb. 2014.00145

This article was submitted to the journal Frontiers in Cellular and Infection Microbiology.

Copyright (C) 2014 Barreto-Bergter and Figueiredo. This is an open-access article distributed under the terms of the Creative Commons Attribution License (CC BY). The use, distribution or reproduction in other forums is permitted, provided the original author(s) or licensor are credited and that the original publication in this journal is cited, in accordance with accepted academic practice. No use, distribution or reproduction is permitted which does not comply with these terms. 